\title{
Neumonía aguda adquirida en la comunidad en adultos: Actualización de los lineamientos para el tratamiento antimicrobiano inicial basado en la evidencia local del Grupo de Trabajo de Sudamérica (ConsenSur II)
}

\author{
Carlos Bantar', Daniel Curcio², Abel Jasovich³, Homero Bagnulo", Álvaro Arango ${ }^{5}$, Luis Bavestrello', \\ Angela Famiglietti? , Patricia García ${ }^{8}$, Gustavo Lopardo ${ }^{9}$, Miriam Losanovscky10, Ernesto Martínez" ${ }^{11}$, \\ Walter Pedreira4, Luis Piñeyro4, Christian Remolif'2, Flavia Rossi' ${ }^{13}$ y Fabio Varón ${ }^{14}$
}

\begin{abstract}
Updated acute community-acquired pneumonia in adults:
Guidelines for initial antimicrobial therapy based on local evidence from the South American Working Group (ConsenSur II)

Community-acquired pneumonia (CAP) in adults is probably one of the infections affecting ambulatory patients for which the highest diversity of guidelines has been written worldwide. Most of them agree in that antimicrobial therapy should be initially tailored according to either the severity of the infection or the presence of comorbidities and the etiologic pathogen. Nevertheless, a great variability may be noted among the different countries in the selection of the primary choice in the antimicrobial agents, even for the cases considered as at a low-risk class. This fact may be due to the many microbial causes of CAP and specialties involved, as well as the different health-care systems effecting on the availability or cost of antibiotics. However, many countries or regions adopt some of the guidelines or design their own recommendations regardless of the local data, probably because of the scarcity of such data. This is the reason why we have developed a guideline for the initial treatment of CAP by 2002 upon the basis of several local evidences in South America (ConsenSur I). However, several issues deserve to be currently rediscussed as follows: certain clinical scores other than the Physiological Severity Index (PSI) have become more popular in clinical practice (i.e. CURB-65, CRB-65); some pathogens have emerged in the region, such as community-acquired methicillin resistant Staphylococcus aureus (CA-MRSA) and Legionella spp; new evidences on the performance of the rapid test for the etiologic diagnosis in CAP have been reported (eg. urinary Legionella and pneumococcus antigens); new therapeutic considerations needs to be approached (i.e. dosage reformulation, duration of treatment, emergence of novel antibiotics and clinical impact of combined therapy). Like in the first version of the ConsenSur (ConsenSur I), the various current guidelines have helped to organize and stratify the present proposal, ConsenSur II.

Key words: Pneumonia, guidelines and respiratory infection.

Palabras clave: Neumonía, guías, infección respiratoria.
\end{abstract}

\section{Conflicto de intereses}

El grupo ConsenSur II declara que el patrocinador no influenció sobre el contenido del documento.

\section{Declaración de transparencia de los miembros del Consensur II}

Los miembros del comité cumplieron los requerimientos del Director General y de los Coordinadores con respecto a la transparencia de la declaración personal de intereses. A continuación se suministra un resumen de la declaración de intereses durante el funcionamiento del panel:

AA recibió honorarios por conferencias de Wyeth INC y respaldo por participar en conferencias de Bayer, Wyeth INC y AstraZeneca. HB recibió respaldo por concurrir a confe-rencias de AstraZeneca, Sanofi-Pasteur, fondos para investigación de Laboratorio Roche. CB recibió fondos de investigación de Laboratorios Bagó, honorarios por conferencias de Wyeth INC y respaldo por concurrir a conferencias de Wyeth INC. LB recibió respaldo por concurrir a conferencias de Bayer, Wyeth INC, GlaxoSmithKline y Merck Sharp \& Dohme. DC recibió honorarios por expositor de Wyeth INC y Laboratorios Bagó y respaldo por concurrir a conferencias de Wyeth INC. PG recibió fondos de investigación de Wyeth INC y respaldo por concurrir a conferencias de Wyeth INC y Merck Sharp \& Dohme. GL recibió honorarios por expositor de Janssen-Cilag y Sanofi-Pasteur, y respaldo por concurrir a conferencias de Bristol Myers Squibb, GlaxoSmithKline, Roche y Janssen-Cilag. EM recibió fondos para investigación de Wyeth INC. LP es miembro del Comité Asesor de GlaxoSmithKline y recibió honorarios por expositor de Boehringer-Ingelheim. FR recibió honorarios por expositor de Wyeth INC, Merck Sharp \& Dohme, Bayer, Sanofi-Aventis y Pfizer. AF, AJ, ML, WP, CR y FV no tuvieron contacto con alguna empresa de la industria farmacéutica. 


\section{Introducción}

L a neumonía adquirida por adultos en la comunidad (NAC) permanece como una de las infecciones más serias que afectan a los pacientes ambulatorios, representando una morbilidad y mortalidad significativa $^{1-2}$. En E.U.A. es la sexta causa principal de muerte. De hecho, se estima que, aproximadamente, 5,6 millones de casos de NAC ocurren cada año en ese país y al menos un millón de ellos requieren hospitalización ${ }^{2-3}$. Además, la NAC es, probablemente, una de las infecciones que afectan a los pacientes ambulatorios para la cual se escribieron la mayor diversidad de lineamientos en todo el mundo ${ }^{4-10}$. Aunque la mayoría de los lineamientos concuerdan en que el tratamiento antimicrobiano se debe ajustar inicialmente a la gravedad de la infección o a la presencia de co-morbilidades y a la epidemiología, se puede notar una gran variabilidad entre los diferentes países en cuanto a la selección de la opción primaria de los agentes antimicrobianos, aún para los casos considerados como de bajo riesgo. Este hecho puede deberse a las múltiples etiologías de la NAC y a las especialidades médicas involucradas en la preparación de las guías, como así también a los diferentes sistemas de asistencia de salud que afectan la disponibilidad o el costo de los antimicrobianos ${ }^{11}$.

A pesar de que los diferentes grupos de lineamientos pueden ser de utilidad para abordar el manejo adecuado de la NAC, cada uno de ellos tiene sus propias fortalezas y debilidades y la mayoría de las recomendaciones se basan en la evidencia local. Aun así, muchos países o regiones adoptan algunos de estos lineamientos o diseñan sus propias recomendaciones, en forma independiente de los datos locales, probablemente debido a la escasez de dichos datos ${ }^{4,12,13}$. Sin embargo, la epidemiología de la NAC, como así también las disponibilidades de asistencia de la salud, pueden variar entre las diferentes regiones, especialmente en los países en desarrollo. Por ejemplo, la selección antimicrobiana recomendada por la mayoría de los lineamientos norteamericanos o europeos está fuertemente influenciada por la probabilidad de implicación de las especies de Legionella. No obstante, en Sudamérica los casos de NAC atribuibles a estos microorganismos fueron infrecuentes ${ }^{14-16}$. Por este motivo desarrollamos lineamientos para el tratamiento inicial de la NAC en el año 2002 sobre la base de varias evidencias locales en Sudamérica ${ }^{17}$. Sin embargo, varios temas merecen discutirse nuevamente en la actualidad, a saber: ciertos puntajes clínicos además del PSI se hicieron más populares en la práctica clínica (por ej. CURB-65, CRB-65) algunos patógenos emergieron en la región, tal como Staphylococcus aureus resistente a meticilina adquirido en la comunidad (SAMR-AC) y Legionella spp; se reportaron nuevas evidencias sobre el desempeño de la prueba rápida para el diagnóstico etiológico de la NAC (por ej. Legionella urinaria y antígenos de Streptococcus pneumoniae); se deben abordar nuevas consideraciones terapéuticas (por ej. reformulación de la dosis, duración del tratamiento, emergencia de antimicrobianos nuevos e impacto clínico del tratamiento combinado). Como en la primera versión del ConsenSur (ConsenSur I), los diferentes lineamientos actuales ayudaron a organizar y a estratificar la presente propuesta, ConsenSur II. Tal como se efectuó en el ConsenSur I, en el presente documento se evitará una discusión extensa sobre numerosos puntos involucrados en la NAC, como por ej.: epidemiología, factores de riesgo, co-morbilidades, pronóstico o lugar de asistencia y solamente se analizarán en el contexto de la elección del tratamiento antimicrobiano inicial, dado que esos aspectos se discutieron en forma amplia en los lineamientos previos ${ }^{4-10}$. Además, el análisis de la NAC en el grupo de los pacientes inmunocomprometidos, como así también las recomendaciones sobre la neumonía asociada a la asistencia de la salud, tuberculosis o cualquier infección fúngica respiratoria, se excluirán del presente documento. Aunque estas situaciones podrían merecer la consideración en el diagnóstico etiológico diferencial en ciertos casos, los lectores pueden consultar la información específica en otro lugar cuando se sospechan tales casos. De hecho, el presente documento intenta ser de utilidad para los médicos que tienen un papel en la práctica clínica habitual que involucra a los pacientes con NAC, tal como médicos clínicos de emergencias, medicina interna y médicos de cuidados intensivos y especialistas neumólogos, infectólogos y microbiólogos.

\section{Métodos}

Se convocó a un comité compuesto por especialistas sudamericanos en enfermedades infecciosas, neumología y microbiología con un fuerte interés y reconocida experiencia en NAC, para establecer un grupo de trabajo (ConsenSur II) a fin de diseñar una actualización de la práctica local basada en la evidencia, para el manejo inicial de la NAC. Se siguieron los procedimientos estándar recomendados por Kish ${ }^{18}$. En resumen, esta actualización se efectuó mediante una búsqueda sistemática de bibliografía tanto en español como en inglés, publicada en las bases de datos Medline y en Literatura Latinoamericana y del Caribe en Ciencias de la Salud (LILACS). La única palabra clave introducida fue el término "neumonía adquirida en la comunidad", pero se hizo hincapié especial en los temas establecidos en la introducción. Además, se incluyeron los resúmenes relacionados con la NAC de los Congresos Internacionales más relevantes, incluyendo aquellos realizados en América Latina. Tres miembros (CB, DC y CR) seleccionaron y clasificaron las evidencias 
y las suministraron al resto del grupo a través de un sitio en internet creado al efecto, que estuvo disponible dos meses antes de la reunión de consenso de tres días efectuada en Argentina del 21 al 23 de agosto del año 2008. Cuando fue posible, se efectuó una evaluación sistemática de la fuerza de la evidencia para respaldar estar recomendaciones. Con el propósito de la simplicidad, se adoptó una modificación de los criterios sugeridos por Gross y cols ${ }^{19}$ (Cuadro 1). A través de estos lineamientos, la calificación aparece como números romanos entre paréntesis después de la recomendación correspondiente.

Después de la reunión de consenso, dos miembros $(\mathrm{CB}$, DC) procedieron a desarrollar un borrador, que circuló entre los miembros para su revisión. Este procedimiento se repitió varias veces hasta que todos los participantes del ConsenSur II aprobaron la versión final. Es de notar que las recomendaciones definitivas surgieron del consenso general. Finalmente, el manuscrito original (ConsenSur I) se remitió al Instituto Argentino de Medicina Basada en Evidencia para ser sometido a una revisión crítica por dos expertos independientes sobre realización de lineamientos, Roberto Lede y Pablo Copertari.

\section{Diagnóstico clínico}

Comentario general. Las infecciones del tracto respiratorio son, probablemente, una de las situaciones más frecuentes que llevan al abuso en la prescripción de antimicrobianos. Tanto el diagnóstico erróneo como la administración de tratamiento a pesar de la falta de infección bacteriana, se informaron como causas principales para el tratamiento antimicrobiano inadecuado en los países desarrollados ${ }^{20,21}$. En los países en desarrollo, incluyendo América Latina, el abuso en la prescripción antimicrobianos se asoció con infecciones respiratorias ${ }^{22}$. De hecho, el reconocimiento adecuado de la NAC, entre otras infecciones respiratorias (es decir, aquellas asociadas con la etiología viral), ya que la NAC bacteriana es una infección que siempre requiere el inicio de tratamiento antimicrobiano.

Recomendación. Los pacientes con tos productiva de esputo, falta de aire, crepitaciones en la auscultación, con o sin evidencia de fiebre o dolor torácico, deben efectuar una radiografía (II). Si se evidencian nuevos infiltrados en la radiografía de tórax, estos pacientes deben considerarse como afectados por una NAC (I).

Fundamento. Fiebre, tos nueva con producción de esputo y dolor de tórax están presentes con frecuencia en los pacientes que muestran alteraciones respiratorias focales al examen físico ${ }^{15,23,24}$. Además, estas características pueden ser de utilidad para evaluar la respuesta precoz al tratamiento inicial en pacientes con NAC pertenecientes

\begin{tabular}{|c|c|}
\hline \multicolumn{2}{|c|}{$\begin{array}{l}\text { Cuadro 1. Fuerza de la evidencia científica que respaldan las } \\
\text { recomendaciones de ConsenSur II (año 2009). Modificadas de Gross y cols* }\end{array}$} \\
\hline Grado de evidencia & Definición \\
\hline 1 & $\begin{array}{l}\text { Datos de al menos un estudio adecuadamente con asignación al azar } \\
\text { y controlado }\end{array}$ \\
\hline ॥ & $\begin{array}{l}\text { Resultados claros de al menos un estudio bien diseñado (incluyendo } \\
\text { estudios de cohorte o caso control) }\end{array}$ \\
\hline III & $\begin{array}{l}\text { Evidencias de opiniones de expertos, series de casos o estudios des- } \\
\text { criptivos }\end{array}$ \\
\hline $\begin{array}{l}{ }^{*} \text { Gross PA, Barret } T L, \\
\text { standards for infectious }\end{array}$ & $\begin{array}{l}\text { yer P, Krause PJ, Martone WJ, McGowan JE Jr, et al. Purpose of quality } \\
\text { ases. Clin Infect Dis 1994; 18: 421-7. }\end{array}$ \\
\hline
\end{tabular}

a una clase de riesgo bajo-moderado, como se observó en un estudio clínico multicéntrico efectuado en Argentina ${ }^{15}$. En dicho estudio, la fiebre, tos productiva y dolor torácico estuvieron presentes en el enrolamiento en $89 ; 58$ y $73 \%$ de 84 pacientes con NAC, respectivamente. Entre los pacientes con éxito clínico, 96\% estuvieron afebriles dentro de los 3 días de tratamiento y la mayoría de ellos resolvió la tos productiva entre el $7^{\circ}$ y el $10^{\circ}$ día después de iniciado el tratamiento. En contraste, dos tercios de los pacientes que se quejaban de dolor torácico pleurítico al enrolamiento, continuaron refiriendo este síntoma al día 3 a 5 del tratamiento. Estos hallazgos son similares a los informados por Metlay y cols ${ }^{24}$.

El diagnóstico diferencial de los síntomas respiratorios inferiores es extenso e incluye causas infecciosas y no infecciosas, y la mayoría de las infecciosas son de origen viral y no requieren tratamiento antimicrobiano. Sin embargo, como se señaló anteriormente, en líneas generales, estas situaciones son una amplia fuente de abuso en la prescripción de antimicrobianos ${ }^{25,26}$. El examen físico para la detección de las crepitaciones no es lo suficientemente sensible ni específico para asegurar el diagnóstico de $\mathrm{NAC}^{27}$. Así, aún en un escenario de recursos limitados, la radiografía de tórax se debe considerar obligatoria en pacientes con sospecha de NAC. Además, la radiografía puede ser ocasionalmente útil para sugerir ciertos diagnósticos alternativos o condiciones subyacentes, como así también para identificar marcadores de un curso más complicado de la enfermedad (es decir, neumonía multilobar o efusión pleural).

Observación. A pesar de que no se efectuaron estudios específicamente diseñados para examinar la confiabilidad de los signos físicos en pacientes con NAC, este tema se debe tener en cuenta dado que se describió un alto grado de variabilidad entre los diferentes observadores y se observó que menos de $40 \%$ de los médicos es capaz de diagnosticar una neumonía sobre la base de un examen 
físico solamente ${ }^{28}$. Sin embargo, algunas declaraciones sobre la radiografía de tórax han resultado dudosas debido a la escasez de estudios que evalúan su sensibilidad para detectar infiltrados pulmonares en pacientes con $\mathrm{NAC}^{29,30}$. De hecho, hasta donde sabemos, solamente un estudio examinó la capacidad de la radiografía de tórax para detectar infiltrados en pacientes con NAC, comparada con la TAC de alta resolución. La radiografía de tórax fue capaz de detectar alteraciones pulmonares en solamente 18 de 47 pacientes $(38 \%)^{30}$. Aún así, el ConsenSur recomienda enfáticamente la radiografía de tórax, debido a las razones declaradas en el fundamento y en los comentarios generales.

\section{Pruebas de laboratorio rutinarias}

Comentario general. La realización inicial de pruebas de laboratorio de rutina en pacientes con sospecha de NAC puede depender del estado clínico de los individuos, la presencia de evidencia epidemiológica específica o la necesidad de efectuar ciertos diagnósticos diferenciales. Además, las variaciones entre los diferentes sistemas de asistencia de la salud en las diferentes regiones también pueden influenciar la relación costo/beneficio de las evaluaciones de rutina del laboratorio en pacientes con NAC de bajo riesgo para tratamiento ambulatorio. En cualquier caso, como se señala a continuación, muchos casos de NAC pueden merecer algunas pruebas de laboratorio de rutina para obtener una aproximación clínica requerida para estratificar a los pacientes antes de elegir el tratamiento antimicrobiano y el lugar de asistencia.

Recomendación. Las pruebas de laboratorio de rutina pueden ser innecesarias para pacientes bajo 50 años de edad, con sospecha de padecer una NAC, sin antecedentes de enfermedades neoplásicas, cerebrovasculares, renales ni hepáticas, insuficiencia cardíaca congestiva, diabetes mellitus y ausencia de las siguientes características: alteración del estado mental, pulso $\geq 125 / \mathrm{lpm}$, frecuencia respiratoria $\geq 30$ respiraciones/min, presión arterial sistólica $<90 \mathrm{~mm} \mathrm{Hg}$ y temperatura cutánea $<35{ }^{\circ} \mathrm{C}$ o $\geq 40^{\circ} \mathrm{C}$. De lo contrario, los pacientes deben efectuar un hemograma completo, evaluación renal (incluyendo concentración de electrolitos séricos) y hepática mínima, glicemia y medición de saturación de $\mathrm{O}_{2}$ (II). Además, todo paciente con co-morbilidades que requieran hospitalización, deben someterse a una prueba serológica para VIH (recomendación del panel).

Fundamento. Existen, como mínimo, dos motivos para efectuar ciertas pruebas de laboratorio de rutina en el grupo de pacientes anteriormente seleccionado. El primero es que algunos de esos resultados, conjuntamente con hallazgos clínicos y radiológicos graves, serán necesarios para evaluar la gravedad de la enfermedad. Este paso puede ser inevitable para decidir el lugar de asistencia y el tratamiento antimicrobiano inicial y para estimar el pronóstico, como sugiere la mayoría de los lineamientos publicados $^{4-10}$. El segundo se basa en la sugerencia de que ciertos hallazgos de laboratorio son pronósticos de un mal resultado en pacientes que presentan NAC. Ciertamente, Fine y cols ${ }^{31}$, establecieron que valores de glicemia $\geq 250$ $\mathrm{mg} / \mathrm{dL}$, sodio $<130 \mathrm{meq} / \mathrm{L}$, nitrógeno ureico en sangre $\geq 30 \mathrm{mg} / \mathrm{dL}$ y $\mathrm{pH}$ arterial $<7,35$ se deben tomar en cuenta para un aumento del riesgo de mortalidad en estos pacientes. En resumen, el ConsenSur considera que a pesar de que las pruebas de laboratorio de rutina podrían ser de relativa importancia para los pacientes con NAC tratados en forma ambulatoria, son obligatorias en los pacientes a hospitalizar o en aquellos en quienes se sospecha un resultado incierto.

Observación. Hasta donde sabemos, no se informaron estudios abordando específicamente la utilidad de las pruebas de laboratorio de rutina en pacientes con NAC que pertenecen a una clase de bajo riesgo. Un estudio clínico efectuado en Argentina incluyó únicamente esta clase de pacientes para ser tratados en forma ambulatoria ${ }^{15}$. En este estudio se efectuaron pruebas de laboratorio durante el enrolamiento y a los 10-17 días después del tratamiento. Aunque estos análisis no probaron el valor para el manejo de la NAC en caso alguno, 3 de 84 pacientes $(3,6 \%)$ presentaron diabetes mellitus, un potencial factor predisponente para la enfermedad del legionario ${ }^{32}$ y dos de ellos desconocían su enfermedad subyacente hasta que ingresaron al estudio. Este hecho debe tenerse en cuenta para la recomendación de las pruebas de laboratorio de rutina, aun si los pacientes pertenecen a una clase de bajo riesgo. Sin embargo, debido al grado limitado de esta situación en esta clase de pacientes, el panel confirma la recomendación de no efectuar pruebas de laboratorio de rutina en individuos que se tratarán en forma ambulatoria.

\section{Estudios microbiológicos}

Comentario general. A pesar de la ventaja aparente de efectuar investigaciones microbiológicas en pacientes con NAC, tal como la detección de microorganismos de importancia epidemiológica o la evaluación de susceptibilidad en especies con sensibilidad impredecible a los antimicrobianos (por ej. S. pneumoniae o Haemophilus influenzae), el costo/efectividad de efectuar los estudios en estos pacientes, tal como cultivo de esputo y de sangre o detección de antígenos y anticuerpos, permanece como controversial. De hecho, la realización de investigaciones microbiológicas parece ser más evidente en pacientes 
para internar, especialmente en la Unidad de Cuidados Intensivos (UCI). Aunque el grado de utilidad de tales investigaciones para guiar la terapia en estos pacientes es desconocida ${ }^{4-10}$ las siguientes evidencias recientes podrían hacer conveniente la prueba de antígeno urinario para Legionella y S. pneumoniae: ciertos antimicrobianos (levofloxacina) probaron ser particularmente eficaces en la NAC por Legionella spp $^{33,34}$; algunos informes sugieren que el resultado clínico de los pacientes con bacteriemia neumocóccica pueden mejorar si se aplica un tratamiento combinado $^{35}$.

Recomendación. No se recomiendan los estudios microbiológicos en los pacientes con sospecha de NAC que se tratarán en forma ambulatoria (II). Todos los pacientes a ser internados en una sala de clínica general o en una institución asistencial deben efectuar cultivo de sangre (dos frascos) y análisis de esputo (tinción de Gram y ZiehlNeelsen y cultivo). En pacientes que ingresen a UCI, se deben efectuar pruebas de muestras séricas pareadas para Chlamydophila pneumoniae, Mycoplasma pneumoniae y antígeno urinario para Legionella spp y $S$. pneumoniae (III). En caso de sospecha epidemiológica o clínica, como así también en pacientes con mal resultado inexplicable, se pueden investigar los siguientes organismos (II): Coxiella burnetii, hantavirus, "virus respiratorios" (virus influenza, virus respiratorio sincicial, adenovirus, virus parainfluenza), Chlamydia psittaci y Pneumocystis jiroveci (ex P. carinii).

Fundamento. Aunque la relación costo/beneficio de efectuar estudios microbiológicos no se aseguró en forma exhaustiva, están bien descritas las evidencias del bajo impacto del conocimiento del patógeno sobre el resultado clínico $^{36}$. Ciertamente, se demostró que es el acierto en la elección de los antimicrobianos activos contra los agentes causales habituales de NAC y no la identificación del patógeno lo que demostró un efecto benéfico sobre el resultado ${ }^{37}$. Además, la corrección del tratamiento antimicrobiano inicial inadecuado de acuerdo con el patógeno identificado posteriormente, no parece afectar el resultado de pacientes con NAC grave ingresados en la $\mathrm{UCI}^{38}$. Estos hallazgos se pueden explicar por el hecho que la demora en instaurar el tratamiento adecuado demostró ser crucial para el aumento de la mortalidad en los pacientes internados con NAC grave ${ }^{39}$ y los resultados microbiológicos raramente están disponibles para respaldar la elección inicial. Además, la identificación del agente causal puede llevar a un cambio del antimicrobiano inicial en $<10 \%$ de los $\operatorname{casos}^{40}$. Sin embargo, los crecientes informes sobre el desempeño del antígeno urinario rápido para Legionella spp y $S$. pneumoniae ${ }^{41-43}$, conjuntamente con la implicancia terapéutica mencionada anteriormente en los comentarios generales y el aumento de los informes de pacientes con NAC atribuible a Legionella spp en la región ${ }^{44-46}$, nos llevó a sugerir estas pruebas en pacientes con NAC que ingresen en la UCI.

Por otro lado, la detección de microorganismos de importancia epidemiológica (es decir C. psittaci, Legionella spp, hantavirus, Leptospira spp o Mycobacterium tuberculosis) o la realización de pruebas de susceptibilidad en especies con sucseptibilidad impredecible a antimicrobianos (es decir S. pneumoniae o H. influenzae) puede ser un tema mayor a considerar. Además, otra ventaja de determinar el agente etiológico de la NAC es la recolección de datos microbiológicos confiables para sentar las bases para ajustar el tratamiento antimicrobiano inicial y diseñar lineamientos adecuados ${ }^{5-10}$, especialmente en aquellas regiones donde los datos locales son escasos. Así, en vista de que Sudamérica parece ser el caso $^{5,12,13,210}$; el panel considera que se debe efectuar un esfuerzo para llegar a un diagnóstico etiológico, al menos en los pacientes a internar o en aquellos que fracasan en la respuesta al tratamiento inicial, como así también en pacientes en quienes se sospecha un resultado incierto. Además, se deben programar estudios a gran escala específicamente diseñados para determinar la etiología de la NAC en aquellas regiones donde faltan datos confiables (es decir, países en desarrollo), incluyendo la búsqueda de patógenos virales emergentes, tal como metapneumovirus humano, bocavirus humano y nuevos coronavirus.

Observación. Se ha debatido largamente, la relación costo/beneficio de efectuar investigaciones microbiológicas en pacientes con NAC, probablemente debido, en parte, al bajo rendimiento en la detección de los diferentes patógenos asociados con esta infección ${ }^{4-10}$. La posibilidad de recuperar un potencial patógeno de NAC del cultivo del esputo, habitualmente no supera el $50 \%{ }^{47-49}$. Además, el hallazgo de un posible patógeno en los cultivos de sangre promedia el $11 \%{ }^{50}$. Sin embargo, se debe observar que la bacteriemia neumocóccica podría no estar necesariamente relacionada con la gravedad de la enfermedad. Ciertamente, en un estudio de NAC en Sudamérica, 51\% de 93 pacientes con bacteriemia neumocóccica pertenecían a una clase de bajo riesgo (A. Jasovich y cols, comunicación personal). Levy y cols ${ }^{51}$, publicaron un trabajo correlacionando los hallazgos bacteriológicos con los patrones radiográficos en 119 adultos inmunocomprometidos con NAC. El rendimiento de los cultivos de esputo y sangre fue solamente de 44 y $12 \%$ respectivamente, por lo que los autores proponen una estrategia pragmática para el manejo inicial de la NAC. Un estudio prospectivo que incluyó 90 pacientes ambulatorios de Argentina evaluó el valor del cultivo del esputo para el diagnóstico etiológico de infecciones del tracto respiratorio inferior. Considerando cualquier crecimiento, la sensibilidad y especificidad fueron de 57 
y $55 \%$, respectivamente. Cuando se adoptó un criterio de "crecimiento preponderante", la especificidad se elevó a $80 \%$, pero la sensibilidad disminuyó a $22 \%{ }^{52}$. En este país se efectuaron dos estudios más recientes y se reconoció un potencial patógeno (incluyendo virus y "microorganismos atípicos") en 51 y $25 \%$ de los casos entre 45 y 84 pacientes con NAC de bajo riesgo, respectivamente ${ }^{14,15}$. Este último fue un estudio clínico prospectivo, en el que se observó el fracaso del tratamiento en dos pacientes. El agente causal se recuperó después del tratamiento en ambos casos ( $S$. pneumoniae en uno y $H$. influenzae en otro $)^{15}$. En los 19 pacientes restantes en quienes se efectuó un diagnóstico etiológico, el conocimiento del resultado microbiológico no afectó el manejo del paciente. Aunque el panel considera que los estudios microbiológicos no se deben efectuar en la práctica clínica en pacientes con NAC con tratamiento ambulatorio, se debe efectuar un esfuerzo para llegar a la etiología en aquellos casos que fracasan en la respuesta al tratamiento inicial. Asimismo, no se evaluó en forma extensiva el costo/efectividad de efectuar la prueba de antígenos urinarios. En un estudio, la realización del antígeno neumocóccico se asoció con una reducción del espectro del tratamiento en $60 \%$ de 92 pacientes internados con NAC en una sala de emergencias ${ }^{53}$.

\section{Etiología}

En la mayoría de la regiones, $S$. pneumoniae corresponde aproximadamente a los dos tercios de los casos de NAC en los cuales se efectúa un diagnóstico del agente etiológico ${ }^{5-10,15,16,52,54-58,210}$. Además, H. influenzae y, en menor grado, Moraxella catarrhalis, como así también bacterias atípicas, están apareciendo como frecuentes agentes causales en varios pacientes de ciertas regiones ${ }^{1,9,14,15,52,60,210}$ y pueden observarse eventuales diferencias en la incidencia de $M$. pneumoniae relacionada con la presencia o ausencia de epidemia al momento del estudio 9 . Probablemente, una de las evidencias más ilustrativas de la relativa frecuencia de patógenos asociados en la NAC, en un meta análisis publicado por Fine y cols ${ }^{61}$. Este estudio analizó 7.079 pacientes adultos que padecían NAC de etiología conocida en E.U.A. y Europa. En general, $S$. pneumoniae fue el patógeno identificado con mayor frecuencia en la mayoría de los estudios (65\%), seguido por H. influenzae (12\%), bacterias "atípicas" (12\%) y $M$. catarrhalis (2\%). Aunque estos datos son similares a los encontrados en América Latina ${ }^{15-16,52,60,62-64}$, se observó una mayor frecuencia de aislados de $H$. influenzae $(20$ a $24 \%$ ) y $M$. catarrhalis (4 a $6 \%$ ) en algunos países de Sudamérica ${ }^{14-15,43}$. Raramente se encontró Legionella spp en América del Sur, pero los informes aumentaron desde el año 2001 hasta la fecha ${ }^{14-16,44-46,60-63}$.

La neumonía aspirativa fue bien examinada por Fine- gold $^{65}$ hace más de una década. Este autor estableció que siempre se debe asumir una microbiota autóctona mixta como etiología en pacientes ambulatorios y demostró que los anaerobios estrictos (por ej.: Prevotella, Porphyromonas, Bacteroides, Fusobacterium y especies de Peptostreptococcus), Streptococcus del grupo viridans y microaerófilos, M. catarrhalis y Eikenella corrodens son los microorganismos involucrados con mayor frecuencia en estos casos. Sin embargo, la opinión actual de algunas autoridades es que estos hallazgos están limitados solamente a cierto subgrupo de pacientes (véase a continuación: neumonía aspirativa).

Finalmente, ciertos pacientes pueden presentar una NAC grave por Pseudomonas aeruginosa (fibrosis quística, bronquiectasias), bacterias aeróbicas gramnegativas (grandes consumidores de alcohol o individuos provenientes de instituciones de asistencia prolongada) y $S$. aureus (mujeres embarazadas o pacientes $>70$ años de edad con antecedentes recientes de influenza, individuos que padecieron traumas o consumidores de drogas inyectables $)^{4-10}$. La frecuencia de los diferentes patógenos informados en varios estudios, se muestra en la Tabla 1.

\section{Resistencia bacteriana}

Streptococcus pneumoniae. La emergencia en todo el mundo de cepas de $S$. pneumoniae con una susceptibilidad disminuida a penicilina, es probablemente uno de los eventos que indujo los más significativos cambios en el campo de las enfermedades infecciosas en las últimas dos décadas ${ }^{66-67}$. Los índices actuales de aislados de $S$. pneumoniae que muestran una reducción de la susceptibilidad a penicilina (S. pneumoniae resistente a penicilina - SPRP) obtenidos por los estudios de vigilancia de los laboratorios de varias regiones diferentes (incluyendo América Latina) pueden variar entre menos de 10\% y más de $50 \%$. Además, se puede presentar una resistencia asociada a otros antimicrobianos en varios aislados de SPRP ${ }^{11,54,68-80}$. Sin embargo, se debe notar que rara vez se tuvo en cuenta la discriminación por edad, muestra clínica y tipo de infección respiratoria (es decir, niños versus adultos, esputo versus sangre o efusión pleural y exacerbaciones de bronquitis crónica versus NAC, respectivamente), en la mayoría de estos estudios. Ciertamente, los aislados de SPRP se observan con mayor frecuencia en niños que en adultos y la diseminación de SPRP desde la primera población a la última parece poco probable ${ }^{81}$. Asimismo, las cepas de SPRP son menos prevalentes entre los cultivos de sangre en comparación con las muestras respiratorias, probablemente debido a la inclusión de pacientes con exacerbaciones agudas de bronquitis crónica en estas últimas muestras clínicas ${ }^{69}$. Además, para estimar el índice de SPRP, todos los informes anteriores 


\begin{tabular}{|c|c|c|c|c|c|c|}
\hline \multirow[b]{2}{*}{ Región (ref) } & \multicolumn{6}{|c|}{ Frecuencia (\%) } \\
\hline & $\begin{array}{l}\text { Streptococcus } \\
\text { pneumoniae }\end{array}$ & $\begin{array}{l}\text { Haemophilus } \\
\text { influenzae }\end{array}$ & $\begin{array}{l}\text { Moraxella } \\
\text { catarrhalis }\end{array}$ & $\begin{array}{l}\text { M. pneumoniae/ } \\
\text { C. pneumoniae }\end{array}$ & $\begin{array}{l}\text { Legionella } \\
\text { especies }\end{array}$ & Otras $^{b}$ \\
\hline E.U.A.-Europa (60) & 65 & 12 & 2 & $7 / 1$ & 3 & 10 \\
\hline Reino Unido (9) & 70 & 10 & 0 & $2,5 / 0$ & 3,8 & 13,7 \\
\hline $\begin{array}{l}\text { Europa, Asia, Sudáfrica, } \\
\text { América Latina (62) }\end{array}$ & 67 & 21,5 & NS & $5,5 / 1,7$ & 0,3 & 13,5 \\
\hline Argentina (15) & 62 & 24 & 4,5 & $9,5 / 0$ & $\mathrm{NI}$ & 0 \\
\hline Argentina (51) & 68 & 20 & 6 & $\mathrm{NI}$ & $\mathrm{NI}$ & 6 \\
\hline Uruguay (59) & 96 & 4 & 0 & $15 / 7$ & $\mathrm{NI}$ & 0 \\
\hline Uruguay (61) & 77 & 10 & 3,5 & $10 / 9$ & $\mathrm{NI}$ & 20 \\
\hline
\end{tabular}

adoptaron el antiguo "punto de corte microbiológico" (es decir, CIM de penicilina $>0,06 \mu \mathrm{g} / \mathrm{ml}$ ) en lugar del actualmente recomendado "punto de corte respiratorio" (es decir CIM de penicilina $>2 \mu \mathrm{g} / \mathrm{ml})^{82}$. De hecho, la interpretación del actual Instituto de Estándares Clínicos y de Laboratorio (Clinical and Laboratory Standards Institute - CLSI) $)^{83}$ para el punto de corte "respiratorio" de CIM para penicilina es $\leq 2,0 \mu \mathrm{g} / \mathrm{ml}$ (susceptible), 4,0 $\mu \mathrm{g} / \mathrm{ml}$ (intermedio) y $\geq 8,0 \mu \mathrm{g} / \mathrm{ml}$ (resistente). Además, a pesar de que se informó una mayor frecuencia global de cepas de SPRP en todo el mundo, no se encontraron cepas que muestren un alto nivel de resistencia a penicilina (es decir CIM $>2 \mu \mathrm{g} / \mathrm{ml}$ ) en los estudios de vigilancia microbiológica antes mencionados, ni en grandes estudios clínicos prospectivos efectuados en pacientes adultos con NAC ${ }^{15,44,84-88}$. En Argentina se efectuó un estudio específicamente diseñado para comparar la frecuencia de SPRP entre 121 adultos con NAC pertenecientes a varios estudios clínicos conducidos en este país entre 1999 y 2000, con el obtenido por dos informes de vigilancia de laboratorios. Solamente dos cepas de $S$. pneumoniae con disminución de la susceptibilidad a penicilina (CIM 0,25 - $1 \mu \mathrm{g} / \mathrm{ml}$ ) se encontraron entre 45 aislados recuperados de pacientes enrolados en los estudios clínicos, mientras que ambos estudios de vigilancia informaron un índice de SPRP de $25 \%$ en el mismo país ${ }^{89}$. Este estudio se extendió a otras provincias de Argentina, como así también a Chile y Uruguay. Se recolectaron datos de 101 NAC bacteriémicas por $S$. pneumoniae y solamente se demostró una cepa con disminución de susceptibilidad a penicilina (CIM $1 \mu \mathrm{g} / \mathrm{ml}$ ) (A. Jasovich y cols, comunicación personal).
Así, en el escenario de las evidencias actuales, como otros $^{82,90-92}$, el panel considera que el impacto clínico de SPRP sobre el manejo de la NAC, al menos en adultos, parece ser un "fantasma" más que la anterior creencia de un problema preocupante. Sin embargo, se debe tener precaución con la bacteriemia neumocóccica en aquellos pacientes infectados por VIH, dado que un estudio de Sudáfrica describió un aumento de la frecuencia de SPRP durante el curso de una década (desde 1986 hasta 1997) entre estos individuos, en comparación con pacien-tes seronegativos para el VIH en quienes no se observó ninguna modificación ${ }^{93}$.

La disminución de la susceptibilidad de $S$. pneumoniae a las cefalosporinas utilizadas con más frecuencia en pacientes con NAC (es decir cefuroxima, cefotaxima o ceftriaxona y en menor grado cefpodoxima, o cefprozil) depende frecuentemente del nivel de resistencia a penicilina. Así, las principales consideraciones para estos fármacos son similares a las establecidas para las penicilinas. Sin embargo, se debe hacer una distinción entre cefotaxima o ceftriaxona y cefuroxima o cefpodoxima y cefprozil, dado que las cepas que muestran un bajo nivel de resistencia a penicilina (es decir, CIM $\leq 2 \mu \mathrm{g}$ / $\mathrm{ml}$ ) parecerían permanecer susceptibles a cefotaxima y ceftriaxona, pero probablemente muestren resistencia clínica relevante a cefuroxima y cefpodoxima o cefprozil. Por cierto, mientras que los índices de resistencia a cefotaxima permanecen por debajo de $4 \%$ en la mayoría de las regiones, las respectivas frecuencias para cefuroxima o cefpodoxima varían entre 10 y $30 \%{ }^{69,74}$. 
La resistencia de $S$. pneumoniae a macrólidos y azálidos, una opción mayor ofrecida por la mayoría de los lineamientos ${ }^{4-10,94}$, está ampliamente diseminada por el mundo, con índices que varían entre 10 y $39 \%{ }^{69,95-97}$. La mayoría de los estudios de vigilancia de laboratorio de América Latina encuentran resistencia a macrólidos en hasta $15 \%$ de las cepas ${ }^{54,70-75,98}$. Un estudio de Argentina que incluyó 262 pacientes adultos con NAC mostró una resistencia a estos fármacos que aumentó de $9 \%$ en los años 1997-1998 a 16\% en los años 2000-2002, principalmente atribuible al mecanismo de eflujo (presencia del gen mef-E) (13 de 19 aislados) ${ }^{99}$. Otro estudio en el mismo país, examinó 138 cepas susceptibles a penicilina y 45 cepas no susceptibles. Los respectivos índices de resistencia a claritromicina entre estos aislados fueron de 4,6 y $35 \%{ }^{100}$. Asimismo, la prevalencia de resistencia a macrólidos en aislados brasileños fue de 2,2 y 12,5\% entre 277 cepas susceptibles a penicilina y 82 cepas no susceptibles $^{75}$. En el Reino Unido, la resistencia de $S$. pneumoniae a macrólidos aumentó de 3\% en 1989 a 12\% en 1998, mientras que la resistencia a penicilina y tetraciclina permaneció sin cambios a través del mismo período 9 . Además, está bien demostrada una estrecha correlación entre la frecuencia de cepas de $S$. pneumoniae resistente a macrólidos y el amplio uso de estos fármacos ${ }^{101-102}$. Un estudio de caso control en cuatro hospitales de E.U.A. y España demostró el significado clínico de la resistencia a macrólidos entre las diferentes infecciones causadas por S. pneumoniae, incluyendo 155 pacientes con NAC. Los autores encontraron que el fracaso del tratamiento con macrólidos, evidenciado por el desarrollo de un brote de bacteriemia, fue más frecuente en pacientes infectados con cepas resistentes o con resistencia intermedia a eritromicina, que en aquellos en quienes se recuperaron cepas totalmente susceptibles ( 22 versus $0 \%$, respectivamente). De 19 pacientes que presentaron fracaso, 6 habían sido tratados con azitromicina, 6 con claritromicina, 5 con eritromicina y 2 con josamicina. Estos fracasos fueron independientes del tipo de resistencia involucrado (es decir, mecanismo de eflujo o metilasa $)^{103}$. Así, parece que este fenómeno está apareciendo como un problema preocupante ${ }^{104-105}$.

Doxiciclina es otra opción primaria propuesta por algunos lineamientos ${ }^{4,5,8,12,94}$. Sin embargo, se informaron índices de resistencia considerables (12 a 40\%) a tetraciclinas para $S$. pneumoniae, aun en regiones a las cuales se dirigían estos lineamientos ${ }^{69}$. En América Latina, la mayoría de las vigilancias de laboratorios informan de índices de resistencia a tetraciclina mayores a $20 \%{ }^{69-71}$. En el estudio de Argentina descrito anteriormente, la resistencia a tetraciclina en S. pneumoniae fue de 21 y $31 \%$ para las cepas susceptibles y no susceptibles a penicilina, respectivamente ${ }^{99}$
Las "quinolonas respiratorias": gatifloxacina, gemifloxacina, grepafloxacina, levofloxacina, moxifloxacina, sparfloxacina y trovafloxacina, se convirtieron en una opción adecuada para el tratamiento de la NAC, dado que son igualmente activas contra $S$. pneumoniae resistente y susceptible a penicilina. Varias de estas quinolonas no se comercializan más. Estos fármacos son mencionados en todos los lineamientos en diferente grado y los índices de resistencia de $S$. pneumoniae permanecen por debajo de $1 \%$ en todo el mundo (incluyendo América Latina $)^{68-75,94,100}$. Sin embargo, varios autores están informando un preocupante aumento en las CIM de las fluoroquinolonas contra $S$. pneumoniae de diferentes regiones ${ }^{106-109}$. Un estudio de Argentina encontró $3 \%$ de resistencia para estas tres "fluoroquinolonas respiratorias" disponibles en América Latina (es decir gatifloxacina, levofloxacina y moxifloxacina) $)^{99}$. Ho y cols $^{110}$, demostraron en un estudio de caso control que el tratamiento previo con levofloxacina fue un factor de riesgo independiente (Índice de probabilidad 10,7) para la colonización o infección por $S$. pneumoniae resistente a fluoroquinolonas. Además, se informó un brote hospitalario de infección del tracto respiratorio inferior causado por una cepa de $S$. pneumoniae resistente a las nuevas fluoroquinolonas en Canadá111. El microorganismo se recuperó sucesivamente de 16 pacientes y los primeros pacientes habían recibido ciprofloxacina (una quinolona con actividad marginal contra S. pneumoniae $\left.{ }^{68,69,82,100}\right)$, como tratamiento inicial. Por lo tanto, se debe enfatizar el potencial de resistencia selectiva de estos fármacos y se debe evitar el uso de quinolonas antiguas (es decir ciprofloxacina $u$ ofloxacina) como tratamiento inicial de la NAC ${ }^{4-10}$. El Grupo de Trabajo Terapéutico de Streptococcus pneumoniae Resistente a Fármacos señaló la necesidad del uso cauteloso de las nuevas quinolonas para limitar la emergencia de aislados resistentes. Los expertos sugieren que estas fluoroquinolonas se limiten solamente a los adultos para quienes uno de los regímenes primarios ya fracasó, a sujetos alérgicos a los agentes alternativos o a pacientes que presenten infección documentada con $S$. pneumoniae altamente resistente a penicilina ${ }^{82}$. En general, el CosenSur II concuerda con estas declaraciones.

Haemophilus influenzae. Esta especie es la tercera causa más común de NAC que requiere hospitalización y se describió más frecuentemente en pacientes con enfermedad pulmonar obstructiva crónica (EPOC) grave o fumadores. La resistencia adquirida más relevante en esta especie es a aminopenicilina mediada por $\beta$-lactamasas, que se puede evitar por el agregado de clavulanato o sulbactam y no afecta la actividad de las cefalosporinas de segunda y tercera generación ${ }^{68-69,75,100}$. En E.U.A., la prevalencia de este fenómeno aumentó sostenidamente 
de $16 \%$ en $1986^{112}$ a $36 \%$ en $1995^{113}$ y a $41,6 \%$ en $1997^{68}$. Entre 1997 y 1999, el programa SENTRY recolectó 6.242 aislados del tracto respiratorio de $H$. influenzae del hemisferio occidental (incluyendo América Latina), Europa y la región Asia-Pacífico. Los índices de resistencia a amoxicilina variaron entre $11,8 \%$ (Europa) y $31,5 \%$ (E.U.A.), siendo de $12,5 \%$ entre 526 cepas de América Latina ${ }^{69}$. Aunque algunos autores establecieron la necesidad de una distinción entre los adultos y los niños para analizar la resistencia a aminopenicilina de $H$. influenzae $e^{113}$, otros no encontraron ninguna diferencia en los índices de resistencia cuando los estratificaron por edad $^{68}$. Sin embargo, a diferencia de $S$. pneumoniae, las diferencias entre los índices de resistencia clínicamente relevantes a amoxicilina informados por los estudios de vigilancia de laboratorio y aquellos encontrados en los estudios clínicos de NAC, pueden ser poco notorios en H. influenzae. Por ejemplo, mientras que la prevalencia de $H$. influenzae resistente a amoxicilina promedió el $20 \%$ en un estudio de vigilancia de un laboratorio multinacional ${ }^{69}$, el índice de resistencia de un estudio clínico que incluyó 337 pacientes con NAC de las mismas regiones se encontró en $10 \%{ }^{60}$. En América del Sur, los estudios de vigilancia demostraron aumento de los índices de resistencia de $H$. influenzae a amoxicilina, hasta $25 \%$ en algunos países ${ }^{72,114}$, mientras que se encontraron niveles de resistencia tan altos como $41 \%$ entre 346 pacientes adultos con NAC en la misma región ${ }^{14}$. Los datos actuales son coincidentes con estos informes previos ${ }^{77-78}$. Por lo tanto, el panel recomienda considerar la resistencia de $H$. influenzae a aminopenicilina mediada por $\beta$-lactamasas, para la selección del tratamiento inicial en pacientes con NAC en quienes se sospecha esta especie como etiología.

De las cinco principales causas bacterianas de NAC, $H$. influenzae es la menos susceptible a macrólidos y azálidos. De acuerdo con los puntos de corte del CLSI, claritromicina se debe considerar como de actividad intermedia contra esta especie, mientras que azitromicina demuestra la mejor actividad ${ }^{83}$. Sin embargo, Jacobs y $\operatorname{cols}^{68}$, señalaron las diferencias observadas cuando los resultados de las CIM de macrólidos y azálidos se interpretan por parámetros in vitro y farmacodinámicos. Por ejemplo, cuando se presumió la susceptibilidad a claritromicina y azitromicina de $H$. influenzae sobre la base de un criterio in vitro, los índices de susceptibilidad fueron de 76,6 y $99,7 \%$, respectivamente. Sin embargo, cuando se aplicó un criterio farmacodinámico, la susceptibilidad se convirtió en $0 \%$ para ambos fármacos. Además, hasta donde sabemos, hasta la fecha no se informaron estudios clínicos que evalúen específicamente el resultado clínico de pacientes con NAC por $H$. influenzae tratados con diferentes agentes pertenecientes a las familias de los macrólidos y azálidos. Por lo tanto, independientemente de los índices de susceptibilidad in vitro, el Consensur II considera que los macrólidos y azálidos no se deben utilizar cuando se sospecha que $H$. influenzae es la etiología en pacientes con NAC.

La resistencia del $H$. influenzae a tetraciclinas se demostró por debajo de $3 \%$ en la mayoría de las regiones (incluyendo América Latina) ${ }^{69}$. Sin embargo, aún debe establecerse el rol de cualquier miembro de este grupo de fármacos para los pacientes en tratamiento por NAC causada por $H$. influenzae $e^{4-10}$. Al igual que los macrólidos y azálidos, el panel considera que las tetraciclinas no se deben utilizar cuando se sospecha esta especie como etiología.

Las fluoroquinolonas, tanto las nuevas como ciprofloxacina, son uniformemente activas contra $H$. influenzae en todo el mundo y son igualmente activas contra las cepas productoras y no productoras de $\beta$-lactamasas ${ }^{68-69,75,100}$. Por lo tanto, estos fármacos parecen ser una opción adecuada para los pacientes tratados por NAC en quienes se sospecha de $H$. influenzae como un patógeno potencial.

Moraxella catarrhalis. Prácticamente todas las cepas de esta especie producen una $\beta$-lactamasa que les confiere un bajo nivel de resistencia a aminopenicilinas. Al igual que con $H$. influenzae, este fenómeno puede ser superado por el agregado de clavulanato o sulbactam y no se afectan las cefalosporinas de segunda o tercera generación. Además, M. catarrhalis permanece uniformemente susceptible a macrólidos y azálidos, tetraciclinas y fluoroquinolonas (incluyendo ciprofloxacina) ${ }^{68-69,75,100}$.

\section{Categorización clínica de los pacientes}

Comentario general. Este paso debe ser el primer objetivo para el manejo de los pacientes con NAC, dado que tanto el fundamento de los estudios adicionales como la definición del tipo y el lugar de asistencia, como así también la elección del tratamiento antimicrobiano inicial, están fuertemente influenciados por el estado clínico

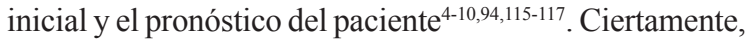
se probaron varios sistemas de clasificación para estimar el riesgo de muerte en la NAC grave, tal como el ampliamente aceptado índice de puntuación de evaluación de asistencia sanitaria aguda fisiológica y crónica (Acute Physiological and Chronic Health Care Evaluation APACHE II) para pacientes en cuidados intensivos, como así también otros dos pronosticadores limitados, el puntaje fisiológico agudo (Acute Physiological Score - APS) y la calificación fisiológica aguda simplificada (Simplified Acute Physiological Score- SAPS). Aunque estos últimos sistemas pueden ser de utilidad para comparar la 
gravedad de la enfermedad y el resultado del tratamiento entre diferentes cohortes de pacientes, carecen de poder predictor para el manejo de los pacientes individuales ${ }^{118}$. Por lo tanto, se desarrollaron estrategias más recientes para estratificar el riesgo de los pacientes con NAC sobre la base de la posibilidad de muerte. El primero fue efectuado por el Comité de investigación de la Sociedad Británica de Tórax - British Thorax Society-BTS) ${ }^{119}$ para identificar pacientes que no solamente requieren internación, sino también merecen la admisión en UCI, mediante la evaluación del estado confusional, uremia, frecuencia respiratoria y presión arterial (actualmente conocido como la clasificación CURB). Esta clasificación fue luego expandida por el agregado de la edad en los pacientes sobre 65 años de edad (CURB-65) ${ }^{120}$. El Equipo de Investigación de Resultados en Pacientes con Neumonía (Pneumonia Patient Outcomes Research Team - PORT) desarrolló otra clasificación (PSI) ${ }^{121}$. De hecho, ambos sistemas son complementarios; mientras que las pautas de la BTS están dirigidas a identificar a los pacientes de alto riesgo para que la gravedad de la enfermedad no se subestime, los pronosticadores PORT están enfocados en el reconocimiento de los pacientes de bajo riesgo para que la gravedad de la enfermedad no se sobre-estime. En cualquier caso, la estratificación clínica inicial de los pacientes efectuada por normas validadas de predicción parece ser un paso inevitable para el manejo adecuado de la NAC ${ }^{4-10,94,115-117}$. Sin embargo, este tema merece una nueva evaluación, dado que nuevas clasificaciones clínicas -además de las pautas CURB y PSI- se hicieron más populares en la práctica clínica (por ejemplo la clasificación CURB modificada, CURB-65, CRB-65, apéndice $)^{120,122}$. Además, recientemente se describieron estrategias para predecir qué pacientes requerirán apoyo respiratorio intensivo o vasopresor (es decir la clasificación SMART-COP, apéndice) ${ }^{123}$. Sobre la base del conocimiento actual sobre la categorización clínica primaria de pacientes con NAC, el panel ConsenSur II modificó su parecer con respecto a la recomendación anterior indicada en la versión del ConsenSur I.

Recomendación. Cada paciente con presunción de NAC se debe estratificar según la clase de riesgo. El panel considera que la clasificación CRB-65 es un sistema de clasificación primaria adecuado. Luego de que el paciente es asignado a una categoría, se debe decidir el lugar de asistencia de acuerdo con ello, como se sugiere en la Figura 1 (II).
Figura 1. Estratificación clínica de pacientes con neumonía adquirida en la comunidad. *Neumonía adquirida en la comunidad.

- Confusión, frecuencia respiratoria, presión arterial, 65 años de edad y mayores (para detalles véase el Apéndice).

¥Presión arterial sistólica, compromiso multilobar en radiografía de tórax, nivel de albúmina, frecuencia respiratoria, taquicardia, confusión, oxigenación y pH arterial (para detalles véase el Apéndice).

"Criterios modificados de la American Thoracic Society (para detalles véase el Apéndice)

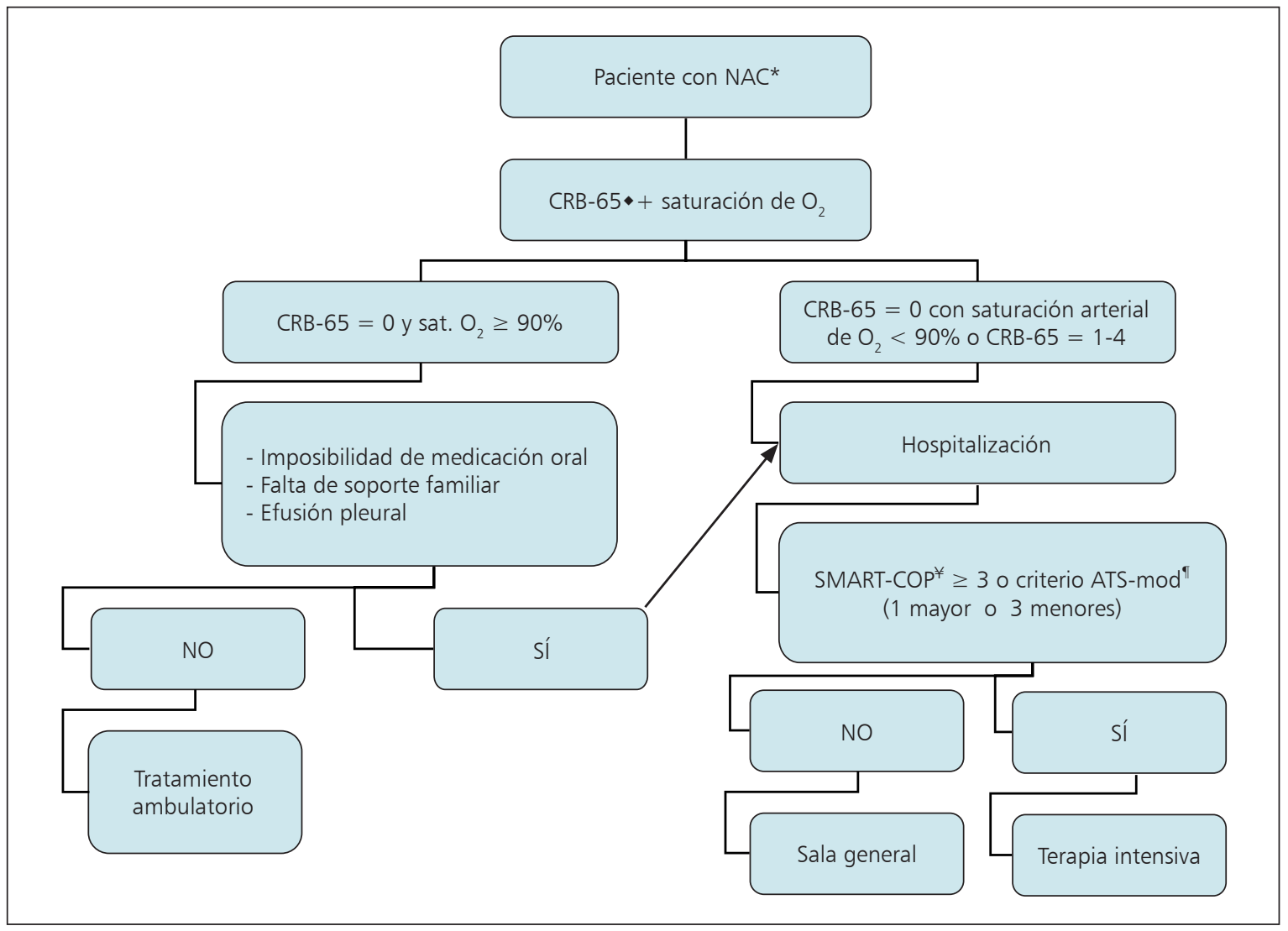


Fundamento. La estratificación clínica de pacientes con NAC está principalmente dirigida a definir el lugar de asistencia mediante la identificación del riesgo de muerte del paciente. De hecho, la decisión de internar a un paciente depende de muchas variables, incluyendo la gravedad de la enfermedad, enfermedades asociadas y otros factores pronósticos ${ }^{61}$. También se deben tener en cuenta la aptitud del apoyo domiciliario y la probabilidad de cumplimiento ${ }^{124}$. Fine y cols, (PSI) ${ }^{125-126}$ desarrollaron un sistema de puntuación para predecir el riesgo de muerte de pacientes con NAC en base a la edad, co-morbilidades y ciertos hallazgos clínicos y de laboratorio. Anteriormente, nosotros adoptamos tales pautas de predicción clínica en el ConsenSur I, debido a que fueron derivadas de datos sobre 14.199 pacientes, se validaron con datos de 38.039 individuos con NAC y probaron ser de utilidad para identificar un paciente a internar ${ }^{125-126}$ o dar de alta del hospital en forma segura ${ }^{125-126}$. Este índice también abordó el desarrollo de normas críticas para el manejo de la NAC en ambientes institucionales ${ }^{127}$. Además, el uso rutinario del PSI se asoció con una mayor proporción de pacientes con bajo riesgo de NAC que se trataron en forma ambulatoria ${ }^{128}$, con los consiguientes beneficios atribuibles al tratamiento ambulatorio en este tipo de pacientes ${ }^{129}$. Ciertamente, el índice PSI es aún el sistema de clasificación más ampliamente utilizado en estudios clínicos de eficacia. Por ejemplo, en un estudio clínico prospectivo efectuado en Argentina, la clasificación PSI fue utilizada con éxito para seleccionar pacientes con NAC con bajo riesgo, para ser tratados en forma oral y ambulatoria durante 7 días ${ }^{15}$. Aun así, se debe notar que además de los pacientes pertenecientes a la clase de riesgo más baja del PSI (es decir PORT I, PSI < 70), la asignación de sujetos con NAC a las restantes clases de riesgo del PSI requerirían varios análisis de laboratorio ${ }^{125-126}$. Por esta razón, el panel revisó la recomendación del sistema de clasificación PSI, dado que la mayoría de los pacientes con NAC concurrirán a la sala de emergencias donde un sistema de clasificación clínica más simple sería de mayor utilidad. Sobre esta base, tanto el sistema de clasificación CURB-65 como el CRB-65 demostraron ser comparables con el PSI ${ }^{130}$. El panel prefiere el CRB-65, dado que no se requieren análisis de laboratorio para este sistema, que presta una aproximación clínica apta para ser utilizada en una sala de emergencias. En cambio, el panel considera que se debe efectuar el esfuerzo de estimar la saturación arterial de oxígeno mediante un oxímetro de pulso en este primer paso en la sala de emergencias ${ }^{131}$. Por lo tanto, el panel recomienda el algoritmo expuesto en la Figura 1 para la estrategia inicial de evaluación de pacientes que se presentan con NAC.

Observación. Se debe notar que las normas de predicción para la neumonía tienen algunas debilidades. Por ejemplo, aunque los expertos extrapolan la necesidad de internación a partir de este sistema de calificación, las pautas realmente se diseñaron para predecir mortalidad y no se efectuó ningún intento de utilizar la estratificación de riesgo con el propósito de definir la necesidad de internación en la UCI. Además, estas pautas incluyen principalmente pacientes en una sala de emergencias de hospital y toma en cuenta pocos pacientes ambulatorios evaluados en el consultorio del médico que se enviaron a su domicilio ${ }^{125-126}$. Rosón y cols ${ }^{132}$, publicaron un ilustrativo estudio que evaluó 533 pacientes con NAC y comparó los criterios de internación convencional con el sistema de calificación PSI. En general, 40\% de los pacientes hospitalizados por los criterios convencionales se asignaron a la categoría de bajo riesgo por el índice PSI. Sin embargo, $60 \%$ de esos pacientes requirieron oxígeno suplementario o tuvieron complicaciones pleurales. Por ende, puede requerirse una evaluación juiciosa del paciente y la decisión final se debe adoptar independientemente del sistema de calificación, tal como lo sugiere la Sociedad Americana de Tórax ${ }^{8}$.

\section{Tratamiento antimicrobiano}

Comentario general. El conocimiento de los potenciales patógenos regionales y de los índices de resistencia bacteriana, como así también la probada seguridad y eficacia de los fármacos, son un tema mayor a tener en cuenta para seleccionar el tratamiento antimicrobiano empírico inicial para administrar a los pacientes que presentan NAC. Además, el estado clínico inicial de los pacientes, la presencia de co-morbilidades, el riesgo de muerte y el lugar de la asistencia también se deben considerar en la decisión final ${ }^{4-10}$. Las sugerencias del ConsenSur están destinadas principalmente a suministrar una recomendación práctica para el tratamiento antimicrobiano inicial de los pacientes con NAC, con la esperanza de procurar una herramienta adecuada para ser utilizada por los diferentes profesionales de la salud involucrados en el manejo de esta infección en América del Sur o en cualquier otro país donde las consideraciones principales de la NAC sean comparables con aquellas de nuestra región. Con este propósito, los pacientes se clasificarán en grupos de acuerdo con el lugar de asistencia y con la presencia de ciertas condiciones de co-morbilidad. Sin embargo, debido a la evidencia descrita en Etiología, el panel, como la mayoría de los lineamientos, cree que $S$. pneumoniae siempre debe ser cubierto por cualquier tratamiento inicial, independientemente de cualquier otra consideración en pacientes con NAC. De cualquier forma, se suministrará un fundamento y una declaración de precaución para respaldar la recomendación de las diferentes elecciones en cada grupo de pacientes. 


\section{Categorización de pacientes para el tratamiento antimicrobiano inicial}

Grupo 1 (CRB-65:0, pacientes ambulatorios). Este grupo incluye pacientes a ser tratados en forma completamente ambulatoria o después de una breve internación (es decir $<4$ días). Los pacientes no deben presentar alguna de las siguientes características: origen en instituciones asistenciales de largo plazo, evidencia de efusión pleural, saturación arterial de oxígeno $<90 \%$, sospecha de neumonía aspirativa, cualquier evidencia que sugiera falta de cumplimiento con un tratamiento oral programado o falta de adaptación del apoyo domiciliario. Este grupo se dividió en dos subgrupos de pacientes:

- Grupo 1a. Pacientes con menos de 60 años de edad, sin evidencia de enfermedad pulmonar obstructiva crónica (EPOC) incluyendo asma, tabaquismo, alcoholismo o diabetes mellitus.

- Grupo 1b. Pacientes de 60 años de edad o mayores, o que presentan cualquiera de los factores predisponentes mencionados anteriormente.

\section{Recomendación}

- Grupo 1a: El panel recomienda amoxicilina a administrar en forma oral como opción primaria en estos pacientes (I). Los macrólidos (es decir claritromicina [eritromicina en mujeres embarazadas]) pueden ser una opción alternativa y deben ser la elección en individuos con alergia conocida a penicilina o si se sospecha que presentan microorganismos "atípicos" (I). Si el paciente debe ser internado debido a la falta de cumplimiento con un tratamiento oral programado, penicilina intravenosa puede ser una opción alternativa (II).
- Grupo $1 b$ : Se recomienda amoxicilina asociada con un inhibidor de $\beta$-lactamasa (es decir clavulanato [I] o sulbactam [II]) administrados por vía oral como opción primaria. Las fluoroquinolonas "respiratorias" disponibles en América del Sur (levofloxacina y moxifloxacina), se proponen como alternativa en estos pacientes (I), como así también en aquellos alérgicos a penicilina y pertenecientes a este grupo. Tanto la dosis como el esquema de administración para el Grupo 1 completo se muestran en la Tabla 2.

Cualquier paciente que presente persistencia de fiebre o que muestre signos o síntomas de deterioro después del tercer día de tratamiento, debe ser re-evaluado en forma clínica. Si no se encuentra una evidencia causal del fracaso del tratamiento, se debe considerar un cambio en el tratamiento (III), especialmente en aquellos pacientes que reciben la opción primaria ( $\beta$-lactámicos), dado que las bacterias "atípicas" no están cubiertas por este esquema.

Fundamento. Las penicilinas son los antimicrobianos más extensamente utilizados y económicos para tratar pacientes con NAC y su seguridad y eficacia están ampliamente documentadas en esta infección. Ciertamente, continúan siendo la opción preferida en pacientes manejados en la comunidad en Europa ${ }^{7,9-11,133}$. Como se señaló en el comentario general, $S$. pneumoniae es el patógeno principal a considerar en la NAC y aún cuando las bacterias "atípicas" puedan ser la etiología, no se espera que ocurran casos fatales en este grupo de pacientes ${ }^{125-126,134}$, por lo que sería posible una modificación del tratamiento en los pocos casos en que no se observe una respuesta clínica precoz y se sospeche la presencia de esos microorganismos. Amoxicilina fue el comparador

Tabla 2. Tratamiento antimicrobiano inicial en pacientes con neumonía leve adquirida en la comunidad, con y sin co-morbilidades, a manejar en forma ambulatoria, grupos 1 b y 1 a, respectivamente

\begin{tabular}{ll} 
Opción de tratamiento & Medicación, dosis y duración de la terapia para los siguientes grupos* \\
\hline & Grupo 1a
\end{tabular}

Primaria Amoxicilina, $500 \mathrm{mg}$ dos veces por día po Amoxicilina, $875 \mathrm{mg}-1.000 \mathrm{mg}$ dos veces por día po 5-7 días

Alternativa (incluye alérgicos a penicilina Claritromicina, 500 mg dos veces por día po 5-7 días o sospecha de bacterias "atípicas")**

Mujeres embarazadas, alérgicos a

penicilina

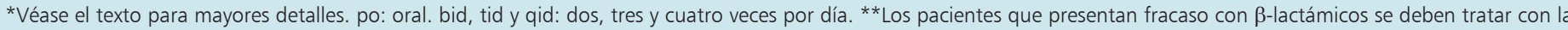
opción alternativa. Si se sospecha Legionella, la duración del tratamiento debe ser de 21 días.
Amoxicilina/clavulanato, $875 \mathrm{mg} / 125 \mathrm{mg}$ dos veces por día po Amoxicilina/sulbactam, $875 \mathrm{mg} / 125 \mathrm{mg}$ dos veces por día po 5-7 días

Levofloxacina, $750 \mathrm{mg}$ diariamente po Moxifloxacina, $400 \mathrm{mg}$ diariamente po 5-7 días

Eritromicina, 500 mg cuatro veces por día po 5-7 días 
en varios estudios clínicos que evaluaron la eficacia de varias fluoroquinolonas nuevas. Todos estos estudios fueron asignados al azar y con doble ciego y la eficacia de amoxicilina fue similar a la de quinolonas en todos ellos, aún en un escenario de "SPRP fantasma"135-137. Esto no sorprende, dado que como se mencionó en Resistencia, la mayoría de las cepas anteriormente llamadas SPRP son actualmente asumidas como clínicamente susceptibles a amoxicilina (punto de corte CIM $8 \mu \mathrm{g} / \mathrm{ml}$ ) cuando causan una infección respiratoria ${ }^{82-83}$ y las cepas realmente resistentes parecen ser infrecuentes en todo el mundo (incluyendo América Latina) ${ }^{69,138-139}$. Sobre la base de estas evidencias y debido a su bajo costo, el panel considera que amoxicilina continúa siendo una opción primaria adecuada en pacientes pertenecientes al Grupo 1a. Una opción alternativa pueden ser los macrólidos, incluyendo aquellos pacientes alérgicos a penicilina. En opinión del panel, se debe seleccionar la claritromicina dado que existen varios estudios clínicos controlados, asignados al azar, doble ciego que demuestran la eficacia de claritromicina oral ${ }^{140-145}$. Eritromicina (excepto en la mujeres embarazadas alérgicas a penicilina) y azitromicina no se recomiendan debido a las razones señaladas a continuación en el punto de observación.

El Grupo 1b incluye pacientes con ciertas co-morbilidades o factores predisponentes. Aunque no se reportaron estudios controlados diseñados para demostrar el aumento de la posibilidad de $H$. influenzae, $M$. catarrhalis y en menor grado, bacterias gramnegativas en estos individuos, actualmente se asume este concepto en la mayoría de los lineamientos ${ }^{4-10}$. En un estudio clínico abierto que incluyó 84 pacientes de Argentina, perteneciente a la clase de riesgo I a III de PSI, 46, 14 y 12\% de los pacientes eran grandes fumadores, alcohólicos o tenían EPOC, respectivamente. En este estudio, la frecuencia de $H$. influenzae y M. catarrhalis entre los pacientes en quienes se efectuó un diagnóstico etiológico, fue de 24 y $5 \%$, respectivamente ${ }^{15}$. Dado que estos microorganismos pueden producir $\beta$-lactamasas en un grado significativo, la recomendación de utilizar una combinación de amoxicilina más un inhibidor de $\beta$-lactamasas parece ser razonable. Al menos dos de tales combinaciones están disponibles en América del Sur. Amoxicilina/clavulanato administrada en forma oral demostró ser eficaz en varios estudios clínicos, aun con un esquema de dos tomas diarias ${ }^{60}$. Amoxicilina/sulbactam, una combinación que se comercializa en Argentina desde 1998 y está actualmente disponible en 29 países, demostró ser eficaz cuando se administra en forma oral dos veces por día para el tratamiento de pacientes con NAC con bajo riesgo. Aunque este estudio fue no controlado, se observaron claros resultados de eficacia $(97,6 \%$, intervalo de confianza 95\% $\left.\left[\mathrm{CI}_{95}\right], 94,3 \%-100 \%\right)^{15}$. Además, las evidencias farmacodinámicas respaldan la aptitud de una esquema de dos veces por día para tratar las infecciones del tracto respiratorio inferior con ambas combinaciones aminopenicilina/inhibidor de $\beta$-lactamasas ${ }^{146-148}$. Debido a la baja actividad de los macrólidos contra $H$. influenzae, el panel recomienda evitar estos fármacos en pacientes del grupo 1b. En cambio, las nuevas fluoroquinolonas pueden ser una opción alternativa en individuos pertenecientes a este grupo, ya que se publicaron varios estudios clínicos controlados para las "quinolonas respiratorias" disponibles en América del Sur (levofloxacina y moxi(loxacina) $)^{144,149-150}$.

Observación. Se deben efectuar algunas consideraciones para el fundamento anterior: se describieron varios fracasos clínicos y microbiológicos en pacientes con bacteriemia neumocóccica y NAC de bajo riesgo tratados con azitromicina $\mathrm{y}$, en forma infrecuente, con claritromicina ${ }^{105,151-152}$. Debido al hecho de que pueden observarse un significativo número de pacientes con bacteriemia neumocóccica en individuos con NAC con bajo riesgo ${ }^{15,90}$, el panel considera que los macrólidos y azálidos orales deben ser considerados una alternativa pero no como opción primaria en estos pacientes; la adecuada eficacia de eritromicina fue demostrada en estudios clínico controlados, asignados al azar, doble ciego ${ }^{153}$ y es un atractivo macrólido debido a su bajo costo. Estas sean probablemente las razones por las cuales este antimicrobiano permanece como el macrólido preferido entre algunos expertos ${ }^{9}$. Sin embargo, debido a la baja tolerabilidad de eritromicina, el panel recomienda limitar este medicamento a las mujeres embarazadas que son alérgicas a penicilina.

Grupo 2 (CRB-65: 1-3, pacientes hospitalizados en sala general, SMART-COP $<\mathbf{3}$, ausencia de criterios ATS modificados para la admisión en UCI). Este grupo de pacientes con NAC con clase de riesgo moderado se dividirá en dos subgrupos:

- Grupo 2a, pacientes a ser manejados en la sala general o en sala de enfermería del hospital.

- Grupo 2b, pacientes a ser manejados en el domicilio (tratamiento domiciliario).

\section{Recomendación}

Grupo 2a. El panel recomienda una aminopenicilina asociada con un inhibidor de $\beta$-lactamasas administrados en forma oral o intravenosa (iv) (es decir, amoxicilina/ clavulanato [I], amoxicilina/sulbactam [III]) o ampicilina/ sulbactam (solamente iv, II). Ceftriaxona o "fluoroquinolonas respiratorias" están propuestas como alternativas (I).

Grupo 2b. El panel ofrece ceftriaxona como opción primaria (III), aunque la combinación de aminopenicilina/ inhibidor de $\beta$-lactamasas o las nuevas fluoroquinolonas se consideran una alternativa adecuada para estos pacientes 


\begin{tabular}{|c|c|c|}
\hline \multirow{2}{*}{ Opción de tratamiento } & \multicolumn{2}{|c|}{ Medicación, dosis y duración de la terapia para los siguientes grupos* } \\
\hline & Grupo 2a & Grupo 2b \\
\hline Primario** & $\begin{array}{l}\text { Amoxicilina/clavulanato, } 875 \mathrm{mg} / 125 \mathrm{mg} \text { tres veces por día po } \\
\text { Amoxicilina/sulbactam, } 875 \mathrm{mg} / 125 \mathrm{mg} \text { tres veces por día po } \\
\text { Ampicilina/sulbactam 1,5g tres veces por día iv 5-7 días }\end{array}$ & Ceftriaxona, $1 \mathrm{~g}$ diario im 5-7 días \\
\hline Alternativa** & $\begin{array}{l}\text { Ceftriaxona, } 1 \mathrm{~g} \text { diario im o iv } \\
\text { Levofloxacina, } 750 \mathrm{mg} \text { diarios po } \\
\text { Moxifloxacina, } 400 \mathrm{mg} \text { diarios po } 5-7 \text { días }\end{array}$ & $\begin{array}{l}\text { Amoxicilina/clavulanato, } 875 \mathrm{mg} / 125 \mathrm{mg} \text { tres veces por día po } \\
\text { Amoxicilina/sulbactam, } 875 \mathrm{mg} / 125 \mathrm{mg} \text { tres veces por día po } \\
\text { Levofloxacina, } 750 \mathrm{mg} \text { diarios po } \\
\text { Moxifloxacina, } 400 \mathrm{mg} \text { diarios po } 5-7 \text { días }\end{array}$ \\
\hline
\end{tabular}

(III). Los esquemas de administración para el Grupo 2 se muestran en la Tabla 3.

Fundamento. Varios estudios demostraron que los patógenos más comunes recuperados de pacientes que pertenecen a este grupo son $S$. pneumoniae (más de la mitad de los casos), $H$. influenzae y, en menor grado, $S$. aureus y Enterobacteriaceae ${ }^{154-156}$. Por ello, la elección del antimicrobiano debe cubrir principalmente estos microorganismos. La eficacia y seguridad, tanto de ceftriaxona ${ }^{154}$ como de amoxicilina/clavulanato ${ }^{156}$, fueron evaluadas en estudios clínicos con asignación al azar que enrolaron esta clase de pacientes. Además, un estudio que incluyó 378 pacientes comparó la eficacia clínica de estos dos fármacos en la "era de SPRP" y no encontró ninguna diferencia entre las dos ramas del estudio (aproximadamente $90 \%$ de éxito clínico para ambos antimicrobianos) ${ }^{157}$. Sin embargo, para el grupo 2a, el panel de consenso prefiere la combinación de aminopenicilina/inhibidor de $\beta$-lactamasa como la opción primaria a ceftriaxona, debido a la potencial variedad y contagio de bacterias gramnegativas con múltiple resistencia a este último fármaco en el ambiente hospitalario ${ }^{158}$. De hecho, la prevalencia de estos microorganismos, especialmente aquellos que producen un amplio espectro de $\beta$-lactamasas, es extremadamente alto en América Latina ${ }^{57,159-162}$. En un hospital de Argentina, el uso de amoxicilina/sulbactam o ampicilina/sulbactam para el tratamiento de pacientes con NAC internados en sala general, aumentó de $21 \%$ en 1999 a $78 \%$ en al año 2001 , mientras que el uso de oximino-cefalosporinas de uso parenteral disminuyó de 47 a 6\%. Durante este período, los índices de resistencia de Klebsiella pneumoniae al espectro extendido de las cefalosporinas disminuyó significativamente desde 62 a $42 \%{ }^{163}$. Es de notar que los estudios que evalúan la eficacia y seguridad de ampicilina/ sulbactam parenteral son escasos e incluyen un número limitado de pacientes ${ }^{164}$. Sin embargo, ampicilina/sulbactam se está utilizando en cierto grado en E.U.A. (es decir $28 \%$ de 67 pacientes con NAC internados en un hospital escuela en Michigan durante un período de 6 meses) ${ }^{165} \mathrm{y}$ amoxicilina/sulbactam se comercializa y utiliza en forma amplia para el tratamiento de la NAC en América Latina desde 1988 hasta la fecha ${ }^{147}$. Por ende, debido al hecho de que la disponibilidad de cualquiera de las combinaciones de aminopenicilina/inhibidor de $\beta$-lactamasas puede depender de las diferentes disponibilidades en la asistencia de salud, el panel considera que ambas combinaciones mencionadas de aminopenicilina/sulbactam pueden ser utilizadas si no se obtiene amoxicilina/clavulanato. Las nuevas fluoroquinolonas también se proponen como una alternativa adecuada para el Grupo 2a, dado que existen varios estudios clínicos con asignación al azar que demuestran su eficacia en este grupo de pacientes ${ }^{85,144,167}$. Sin embargo, como lo señalamos nosotros (véase la sección Resistencia) y otros ${ }^{82}$, se debe tener en cuenta la potencial variedad de la resistencia bacteriana a estos agentes. Por ende, el panel prefiere posicionar a las fluoroquinolonas como una opción alternativa en lugar de la opción primaria.

Para el Grupo 2b, las opciones propuestas son similares a las indicadas anteriormente, por lo que el fundamento para el grupo $2 \mathrm{a}$ puede ser aplicable al Grupo $2 \mathrm{~b}$. No obstante, debido a los diferentes grupos de pacientes, es necesario establecer una consideración mayor. En opinión del panel, ceftriaxona debe ser la opción primaria en pacientes a ser manejados en el domicilio o en hogares de ancianos debido a que su favorable farmacocinética permite una inyección en bolo una vez por día con un 
aceptable éxito clínico (Nathwani y cols, 2000). Bagnulo y cols, describieron una exitosa experiencia con el uso de ceftriaxona para tratar 253 pacientes uruguayos con NAC leve a moderada en el domicilio después de una breve hospitalización ${ }^{169}$.

Observación. Cualquier paciente tratado con $\beta$-lactámicos que persista con fiebre o muestre signos o síntomas de deterioro después del tercer día de tratamiento, debe ser re-evaluado clínicamente. Si no se encuentra una causa evidente de fracaso del tratamiento, se debe considerar la modificación del tratamiento para cubrir las bacterias "atípicas" (es decir fluoroquinolonas o el agregado de macrólidos). Efectivamente, se destacó la necesidad de tener en cuenta la posibilidad de estos microorganismos como el patógeno causal en pacientes hospitalizados con $\mathrm{NAC}^{170}$. Además, se sugirió que el uso de un macrólido como parte del tratamiento inicial en pacientes con NAC internados en el hospital "parece asociarse con una menor estadía"171. Por otro lado, un estudio efectuado en Johns Hopkins Hospital durante el año 1991, demostró que la mortalidad entre 29 pacientes con NAC y la evidencia de bacterias "atípicas" fue virtualmente cero, aun cuando solamente cuatro de estos pacientes recibieron antimicrobianos activos contra estos patógenos (es decir macrólidos o tetraciclinas) ${ }^{134}$. Además, no se informó una frecuencia significativa de Legionella spp, un potencial patógeno fatal ${ }^{172-173}$ en América del Sur ${ }^{14,16,44-46}$. Por lo tanto, el grupo de consenso considera que la cobertura inicial de bacterias "atípicas" es innecesaria y baja relación costo/efectividad, en pacientes pertenecientes al Grupo 2. Además, no se sugiere la cobertura de rutina inicial de SAMR-AC. Aunque se describieron algunos casos de neumonía causada por este patógeno en América Latina $^{174-175}$, la frecuencia de SAMR-AC entre pacientes con neumonía en esta región no justifica la inclusión de una cobertura específica en el tratamiento inicial. El panel considera que los pacientes con sospecha de neumonía por SAMR-AC podrían ser tratados con medicamentos antiguos, tal como vancomicina, clindamicina (cepas susceptibles) y cotrimoxazol ${ }^{174}$, o algunos más nuevos como linezolid y tigeciclina ${ }^{176-178}$.

Grupo 3 (CRB-65: 2-4, pacientes hospitalizados en UCI, SMART-COP $\geq 3$, cumple los criterios ATS modificados para admisión en UCI). Este grupo incluye pacientes con NAC grave que requieren la internación en UCI y se deben dividir en pacientes sin riesgo o con riesgo de NAC causada por P. aeruginosa (Grupo $3 a y$ Grupo 3b, respectivamente).

\section{Recomendación}

- Grupo 3a. El panel de consenso recomienda una aminopenicilina asociada con un inhibidor de $\beta$-lactamasa (iv) más un macrólido o una "fluoroquinolona respiratoria” (iv) (I, II, III). Se propone el reemplazo de la combinación aminopenicilina/inhibidor de $\beta$-lactamasa por ceftriaxona como opción alternativa (I, II, III). Se podría considerar el cambio a tratamiento oral luego de evidenciarse una respuesta clínica favorable y que el paciente pruebe ser capaz de tolerar un tratamiento oral con buena bio-disponibilidad (I, II, III) (véase a continuación en la sección específica para cambio de tratamiento). 
- Grupo 3b. El panel recomienda cefepime o piperacilina/tazobactam más amikacina y un macrólido o más levofloxacina (si no está disponible, podría utilizarse ciprofloxacina en su lugar) como la opción primaria (II, III). En forma alternativa, los $\beta$-lactámicos contra Pseudomonas sp antes mencionados se pueden reemplazar por ceftazidima (solamente si no están disponibles, III).

Los esquemas de administración para el grupo 3 se muestran en la Tabla 4.

Fundamento. Se debe notar que la mayoría de las recomendaciones anteriores se basan en trabajos descriptivos (incluyendo algunos estudios de caso-control) o en consenso de expertos. De hecho, hasta donde sabemos, los estudios prospectivos, con asignación al azar, específicamente diseñados para aseverar la seguridad y eficacia de los diferentes regímenes para el tratamiento de la NAC en pacientes internados en la UCI, son $\operatorname{raros}^{4-10}$. Para el Grupo 3a, tanto el fundamento mencionado anteriormente para el Grupo $2^{109-118}$ como algunas evidencias adicionales ${ }^{179}$ sostienen la recomendación de $\beta$-lactámicos. Se informaron bacterias "atípicas" con un amplio rango de frecuencias entre estos pacientes (véase Tabla 3 de ref 6). Además, aparte de la potencial letalidad de Legionella spp ${ }^{172-173,180}$, un estudio sugiere que la incidencia de este patógeno en la NAC graves está siendo reemplazada por otras baterías "atípicas", tales como $M$. pneumoniae y $C$. pneumoniae ${ }^{181}$. En un estudio de Uruguay, el índice de prevalencia de estos dos microorganismos entre 80 pacientes con NAC internados en la UCI fue de 9 y $10 \%$, respectivamente ${ }^{62}$, mientras que la respectiva frecuencia entre 39 pacientes con NAC grave en Argentina fue de 5 y $8 \%{ }^{14}$. Por ende, en vista del alto índice de mortalidad de la NAC grave, aparece como obligatoria la inclusión de un antimicrobiano de probada actividad contra las baterías "atípicas", tales como fluoroquinolonas o macrólidos, en el tratamiento inicial ${ }^{4-10}$. En forma acorde, se revisó el rol de las nuevas fluoroquinolonas o de un macrólido ${ }^{39,182-183}$. Un reciente estudio prospectivo demostró que entre pacientes con NAC grave ingresados en la UCI, sólo aquellos que presentaron shock se beneficiaron (es decir, se logró un menor índice de mortalidad) por el tratamiento combinado. Es de notar que se observó dicho beneficio por el agregado de macrólidos más que de fluoroquinolonas, a los antimicrobianos $\beta$-lactámicos ${ }^{184}$. Por otro lado, levofloxacina probó ser más eficaz que los macrólidos para el tratamiento de los pacientes con NAC por Legionella $\mathrm{spp}^{185}$. Por lo tanto, el panel estimó que solamente debía considerarse cualquiera de estas dos clases de fármacos para cubrir las bacterias "atípicas" en pacientes internados en UCI. De hecho, consideramos que en pacientes con NAC y shock, se debe agregar un macrólido, pero en aquellos en quienes se confirma una Legionella sp como patógeno causal, se deben preferir las fluoroquinolonas en su lugar.

El Grupo 3b representa uno de los tipos de pacientes más difíciles de abordar, dado que prácticamente todos los patógenos potenciales, incluyendo aquellos encontrados con baja frecuencia en la NAC, tales como $P$. aeruginosa, deben cubrirse en el tratamiento inicial. Por lo tanto, es necesario un antimicrobiano con probada actividad contra estas especies y contra $S$. pneumoniae, como así también el agregado de un fármaco eficaz contra bacterias "atípicas", por lo que en estos casos con frecuencia se requiere un esquema triple $\mathrm{e}^{4-10}$. Existen -al menos- cuatro motivos para situar a cefepime o a la combinación piperacilina/ tazobactam sobre ceftazidima:

- Ceftazidima es inactiva contra las bacterias grampositivas (incluyendo S. pneumoniae).

- Tanto cefepime como piperacilina/tazobactam probaron tener menos probabilidad que ceftazidima de seleccionar y difundir microorganismos con múltiple resistencia dentro del ambiente hospitalario ${ }^{186-187}$.

- Se publicó -al menos- un estudio clínico con asignación al azar, de cada uno, evaluando cefepime y piperacilina/tazobactam para el tratamiento de la NAC ${ }^{188-189}$.

- Cefepime probó ser más activo que ceftazidima contra las bacterias gramnegativas (incluyendo $P$. aerugino$s a)^{160,190}$.

El agregado de amikacina a un $\beta$-lactámico, especialmente cefepime, demostró sinergia bactericida contra $P$. aeruginosa, aun en aquellas cepas resistentes a carbapenems ${ }^{190}$. Por el contrario, dicha sinergia se observó raramente entre aminoglucósidos y fluoroquinolonas o carbapenems $^{191-192}$, por lo que el beneficio de agregar un aminoglucósido a una fluoroquinolona o a carbapenem permanece incierto. Por ende, además de la combinación de un $\beta$-lactámico contra Pseudomonas sp con amikacina $\mathrm{y}$ en menor grado con una fluoroquinolona, el panel no puede aseverar la buena relación costo/efectividad de cualquier otro esquema doble para el tratamiento de pacientes con sospecha de NAC grave causada por $P$. aeruginosa. Si se utiliza un carbapenem contra estas especies, el panel considera que meropenem sería preferible a imipenem, debido a su mayor actividad contra este patógeno ${ }^{193} \mathrm{y}$, por lo tanto, su mayor probabilidad de alcanzar el objetivo farmacodinámico requerido para los carbapenems.

\section{Terapia secuencial}

La relación costo/beneficio del cambio de tratamiento parenteral a tratamiento oral en pacientes con NAC de riesgo moderado a alto, está convirtiéndose en un tema 
importante ${ }^{194-195}$. Sin embargo, relativamente pocos estudios con asignación al azar se diseñaron específicamente para encarar este tema ${ }^{196-199}$. Sin dudas, la principal pregunta a responder es: ¿cuándo se puede cambiar en forma segura la vía de administración del tratamiento? El panel concuerda con la mayoría de los expertos en que, aunque el momento del cambio está determinado principalmente por la capacidad del paciente de tolerar una dosis oral, dicho cambio no se debe intentar antes de los primeros tres días de tratamiento parenteral y se debe limitar a los pacientes clínicamente estabilizados, que presentan una respuesta clínica favorable (por ej.: disminución de la tos, y de la producción de esputo, mejoría o resolución de los síntomas, estabilidad hemodinámica y de la fiebre $)^{5-10}$.

Otro tema a considerar es el fármaco a utilizar para el cambio, y si la opción oral debe ser el mismo antimicrobiano administrado en forma iv. Un estudio con asignación al azar que incluyó 687 pacientes hospitalizados con NAC moderada a grave, comparó la eficacia y seguridad de moxifloxacina contra amoxicilina/clavulanato (con o sin claritromicina) administrada en forma iv durante el menos tres días, seguido de moxifloxacina y amoxicilina/clavulanato oral, respectivamente. Aunque se observaron buenos índices de éxito clínico (> 80\%) con ambos regímenes, se encontró una eficacia significativamente mayor para moxifloxacina en comparación con amoxicilina/clavulanato $(93,4$ versus $85,4 \%, \mathrm{p}=$ $0,004)$. Esta superioridad se observó independientemente de la gravedad de la neumonía y con o sin inclusión de un macrólido en el tratamiento combinado. Sin embargo, en este estudio no se efectuó una clara estratificación clínica de los pacientes (por ej.: enfermedad grave o moderada $)^{85}$. Fogarty y cols ${ }^{166}$, evaluaron la eficacia y seguridad de gatifloxacina, administrada en forma de cambio a 141 pacientes internados ( $71 \%$ con NAC grave), contra ceftriaxona (142 pacientes internados, $75 \%$ con NAC grave). Los índices de curación clínica fueron mayores al 90\% para ambos regímenes. Asimismo, se evaluó la aptitud de levofloxacina para el tratamiento secuencial en algunos estudios, con buenos resultados ${ }^{194-195}$. Uno de esos estudios fue un gran ensayo de intervención clínica que incluyó 1.743 pacientes para evaluar una vía crítica para el tratamiento de la neumonía en nueve hospitales canadienses. Los autores demostraron una reducción de 1,7 días en la duración de la estadía con el uso de una vía crítica ${ }^{194}$. Otro estudio doble ciego, que incluyó 351 pacientes, comparó la eficacia de un esquema secuencial de ceftriaxona más amoxicilina/ clavulanato iv-oral contra monoterapia con ertapenem. Los índices de éxito clínico fueron mayores al 90\% para ambos regímenes ${ }^{110}$. Aun así, el grupo de consenso recomienda a los médicos precaución y que verifiquen una buena bio-disponibilidad oral de los medicamentos cuando utilicen una estrategia secuencial parenteral-oral para el tratamiento de pacientes con NAC grave y no recomienda cambiar a tratamiento oral en pacientes críticamente enfermos, especialmente en aquellos que presentan inestabilidad hemodinámica.

Observación. Gleason y cols ${ }^{39}$, analizaron el efecto de la mayoría de los regímenes mencionados anteriormente para el Grupo 3 (excepto las nuevas fluoroquinolonas) sobre el resultado clínico en pacientes añosos internados con neumonía adquirida en la comunidad (9.751 pacientes) o en una institución de asistencia de largo plazo (3.194 pacientes). En este estudio se encontró que tres regímenes estuvieron estadísticamente asociados con una menor mortalidad a 30 días: ya fuera cefuroxima o una cefalosporina de tercera generación no activa contra Pseudomonas sp asociada con un macrólido y una fluoroquinolona "antigua" (ciprofloxacina $\mathrm{u}$ ofloxacina) solamente. Tanto la asociación de un $\beta$-lactámico/inhibidor de $\beta$-lactamasa más un macrólido, como un aminoglucósido más cualquier otro agente, se asociaron con un aumento de la mortalidad a 30 días. Aunque estos resultados puedan sugerir que algunos regímenes antimicrobianos pueden mejorar la calidad de la asistencia por disminución de la mortalidad, se debe señalar un importante sesgo sistemático en el estudio anterior, como lo señaló Dowell ${ }^{200}$. Ciertamente, la Tabla 3 del artículo de Gleason y cols ${ }^{39}$, evidencia claramente que los médicos clínicos seleccionaron el tratamiento inicial influenciados por la gravedad de la enfermedad. Por ejemplo, los macrólidos en forma única (uno de los regímenes asociados con la menor mortalidad a 30 días) se administraron aproximadamente 7,5 veces con más frecuencia a pacientes en clase de riesgo II a IV de PSI, en comparación con aquellos con el mayor riesgo de mortalidad (clase de riesgo V de PSI). El mismo sesgo se puede observar para las cefalosporinas de segunda generación (ya sea solas o con el agregado de un macrólido), mientras que se puede observar el efecto opuesto para la combinación $\beta$-lactámico/inhibidor de $\beta$-lactamasa o para los regímenes que contienen aminoglucósidos. El impacto del desvío puede evidenciarse fácilmente por el hecho de que, entre los pacientes con clase de riesgo $\mathrm{V}$ de PSI, el uso de macrólidos solamente, se asoció con una menor mortalidad que los macrólidos más una cefalosporina de tercera generación (22,2 versus $28,6 \%$, respectivamente). Asimismo, en el grupo completo de pacientes, los índices de mortalidad para macrólidos solamente y asociados con la combinación de aminopenicilina/inhibidor de $\beta$-lactamasa fueron de 9,8 y $22,2 \%$, respectivamente. Otro estudio más reciente sugiere que el tratamiento combinado puede reducir el índice de mortalidad entre los pacientes con NAC y bacteriemia neumocóccica. Como en la cohorte de Gleason ${ }^{39}$, se 
puede observar un sesgo de ingreso en la Tabla 1 de este artículo, dado que la frecuencia de pacientes infectados con VIH fue prácticamente cuatro veces mayor en la rama de sujetos tratados con $\beta$-lactámico solamente que en la rama que recibió tratamiento combinado ${ }^{201}$. Por lo tanto, el panel considera que los estudios que encaran "el mejor tratamiento" para pacientes con NAC grave, de acuerdo a lo estimado por el índice de mortalidad, deben ser rigurosamente controlados en cuanto a gravedad de la enfermedad y que este tema permanece por dilucidar

Para este Grupo 3, el panel ofrece una opción alternativa apta y auspiciosa: las nuevas fluoroquinolonas. Sin embargo, dos temas importantes merecen una breve discusión. Los potenciales efectos adversos graves relacionados con algunas fluoroquinolonas nuevas tal como mareos, hipoglicemia, prolongación del intervalo QT corregido, fototoxicidad y hepatotoxicidad, permanecen como una preocupación importante ${ }^{6}$. Aunque la mayoría de los efectos adversos graves antes mencionados fueron solamente descritos en forma escasa para levofloxacina -la fluoroquinolona respiratoria utilizada más ampliamente hasta la fecha- se informaron varios fracasos del tratamiento con este fármaco. Por ejemplo, se describieron en detalle cuatro casos incluyendo dos pacientes sin antecedentes de tratamiento con fluoroquinolonas ${ }^{202}$. De hecho, recientemente se revisó un total de 20 casos bien documentados de fracasos clínicos ${ }^{203}$. Sobre la base de estas y otras evidencias ${ }^{111}$, el grupo de consenso considera que las "quinolonas respiratorias" se deben evitar en el tratamiento de pacientes con antecedentes de tratamiento con fluoroquinolonas, especialmente ciprofloxacina.

\section{Neumonía por aspiración}

Aunque todos los casos de neumonía suponen una "micro aspiración" previa de contenido orofaríngeo a la laringe y al tracto respiratorio inferior, este tema está referido especialmente a aquella aspiración evidente de contenido orofaríngeo y gástrico que ocurre en pacientes ambulatorios; es decir la neumonía por aspiración precedida por una injuria química (síndrome de Mendelson), o una aspiración de gran volumen luego de una obstrucción con un cuerpo extraño o líquidos. El diagnóstico clínico diferencial, como así también el tratamiento general específico, puede consultarse en otro lugar ${ }^{204}$; la recomendación del panel sólo está dirigida a aquellos casos que requieren tratamiento antimicrobiano.

Recomendación. El grupo de consenso recomienda la combinación de aminopenicilina/inhibidor de $\beta$-lactamasa como primera opción y clindamicina más ciprofloxacina como la alternativa (II, III).
Fundamento. Hasta la década de 1990, se asumió que los anaerobios estrictos estaban uniformemente asociados con la neumonía por aspiración ${ }^{65}$. Sin embargo, las evidencias actuales sugieren que el rol de estos microorganismos puede estar limitado solamente a los pacientes que presentan alcoholismo crónico, secreción pútrida o enfermedad periodontal ${ }^{204-206}$. En cambio, en pacientes con un síndrome de aspiración adquirido en la comunidad predominan S. pneumoniae, S. aureus, $H$. influenzae y Enterobacteriaceae ${ }^{205}$. Además, Streptococcus spp facultativos y microaerófilos pueden tener un papel en algunos $\operatorname{casos}^{204}$. Hasta donde sabemos, los únicos estudios comparativos que evalúan el tratamiento antimicrobiano para infecciones pulmonares por anaerobios se efectuaron en pacientes con absceso de pulmón. Estos estudios demostraron que clindamicina es superior a penicilina ${ }^{207-208}$. Amoxicilina/clavulanato también probó ser efectiva para el tratamiento de la neumonía por aspiración con absceso pulmonar $^{209}$. En vista de que el absceso pulmonar podría no ser evidente en forma precoz y debido a que otros microorganismos que no sean anaerobios pueden asociarse con la neumonía por aspiración, el ConsenSur recomienda cualquiera de las combinaciones de aminopenicilina/ inhibidor de $\beta$-lactamasa como opción principal y sugiere el agregado de ciprofloxacina a clindamicina como un esquema alternativo.

\section{Resumen}

La neumonía adquirida por adultos en la comunidad (NAC) es, probablemente, una de las infecciones que afecta a los pacientes ambulatorios para la cual se ha escrito la mayor diversidad de lineamientos en todo el mundo. La mayoría de ellos concuerdan en que el tratamiento antimicrobiano debe ser ajustado inicialmente de acuerdo con la gravedad de la infección o con la presencia de co-morbilidades y el patógeno etiológico. Aun así, se puede notar una gran variabilidad entre los diferentes países en la selección de la elección primaria de los agentes antimicrobianos, incluso en los casos considerados como de bajo riesgo. Este hecho puede deberse a las múltiples causas microbianas de la NAC y las especialidades médicas involucradas, como así también los diferentes sistemas de asistencia de salud que afectan la disponibilidad o el costo de los antimicrobianos. No obstante, muchos países o regiones adoptan alguno de los lineamientos o diseñan sus propias recomendaciones independientemente de los datos locales, probablemente debido a la escasez de dichos datos. Por esta razón desarrollamos lineamientos para el tratamiento inicial de la NAC hacia el año 2002, sobre la base de varias evidencias locales en Sudamérica (ConsenSur I). Sin embargo, varios temas merecen discutirse nuevamente 
como sigue: ciertos puntajes clínicos además del Índice Fisiológico de Severidad (IFS) se hicieron más populares en la práctica clínica (por ej. CURB-65, CRB-65); emergieron algunos patógenos en la región, tal como Staphylococcus aureus resistente adquirido en la comunidad (SAMR-AC) y Legionella spp; se reportaron nuevas evidencias sobre el desempeño de la prueba rápida para el diagnóstico etiológico de NAC (por ejem- plo, Legionella urinaria y antígenos de Streptococcus pneumoniae); deben abordarse nuevas consideraciones terapéuticas (por ej.: reformulación de la dosis, duración del tratamiento, emergencia de antimicrobianos nuevos e impacto clínico del tratamiento combinado). Como en la primera versión del ConsenSur (ConsenSur I), los diversos lineamientos actuales ayudaron a organizar y estratificar la presente propuesta, ConsenSur II. 


\section{Referencias}

1.- National Center for Health Statistics. National hospital discharge survey: Annual summary 1990. Vital Health Stat 1998; 13: 1-225.

2.- Niederman M S, Peter S P. Update in pulmonary medicine. Ann Intern Med 1998; 128: 208-15.

3.- Niederman M S, McCombs J S, Unger A N, Kumar A, Popovian R. The cost of treating community-acquired pneumonia. Clin Ther 1998; 20: 820-37.

4.- Calmaggi A, Clara L, González Arzac M, López Furst M J, Levy Hara G. Guías para el diagnóstico y tratamiento de la neumonía adquirida en la comunidad en adultos. Infect Microbiol Clin 2000; 12: S6-S30.

5.- Bartlett J G, Dowell S F, Mandell L A, File T M Jr, Musher D M, Fine M J. Practice guidelines for the management of communityacquired pneumonia in adults. Clin Infect Dis 2000; 31: 347-82.

6.- Mandell L A, Marrie T J, Grossman R F, Chow A W, Hyland R H. Canadian guidelines for the initial management of communityacquired pneumonia: an evidence-based update by the Canadian Infectious Diseases Society and the Canadian Thoracic Society. Clin Infect Dis 2000; 31: 383-421.

7.- Huchon G, and European Study on Community-acquired Pneumonia. Guidelines for management of adult community-acquired lower respiratory tract infections. Eur Respir J 1998; 11: 986-91.

8.- Niederman M S, Mandell L A, Anzueto A, Bass J B, Broughton W A, Campbell GD, et al. Guidelines for management of adults with community-acquired pneumonia. Am J Resp Crit Care Med 2001; 163: 1730-54.

9.- BTS Guidelines for the Management of Community Acquired Pneumonia in Adults. Thorax 2001; 56 (Suppl 4): iv1-iv64.

10.- SEPAR, Spanish Thoracic Society. National recommendations for diagnosis and treatment of community acquired pneumonia. Barcelona, Spain. Ediciones Doyma 1992.

11.- Woodhead M. Community-acquired Pneumonia Guidelines. An international comparison. A view from Europe. Chest 1998; 113: S183S-S187.

12.- Luna C M, Efron E D, Schiavi E, Gene R J, Famiglietti A, Jolly E C, et al. Communityacquired pneumonia in adults. Clinical practice guideline for Argentina. Study Group on Community Acquired Pneumonia. Medicina (Buenos Aires) 1997; 57: 343-55.

13.- Da Cunha C A, Sader H S, Nicodemo A C. Brazilian Society for Infectious Diseases Practice Guidelines Committee. Antimicrobial therapy for community-acquired pneumonia in adults. Braz J Infect Dis 2002; 6: 82-7.

14.- Luna C M, Famiglietti A, Absi R, Videla A J, Noqueira F J, Fuenzalida A D, et al.
Community-acquired pneumonia: etiology, epidemiology, and outcome at a teaching hospital in Argentina. Chest 2000; 118: 1344-54.

15.- Jasovich A, Soutric J, Morera G, Mastruzzo M, Vesco E, Izaguirre M, et al. Efficacy of amoxicillin-sulbactam, given twice-a-day, for the treatment of communityacquired pneumonia. A clinical trial based on a pharmacodynamic model. J Chemother 2002; 14: 591-6.

16.- Cabello H, Cortés C, Ruiz M, Jover E, Rivera F, Segovia E, et al. Community acquired pneumonia. Report of 8 cases of severe pneumonia by serogroup 1 Legionella pneumophila in Chile. Rev Med Chile 2002; 130: 309-13.

17.- Bantar, C, Bavestrello, L, Curcio, D, Jasovich A, Absi R, Bagnulo H, et. al. Acute community-acquired pneumonia in adults: guidelines for initial antimicrobial therapy based on local evidence from a South American Working Group (ConsenSur). J Chemother 2002; 14 (Suppl 4): 1-22.

18.- Kish M A. Guide to development of practice guidelines. Clin Infect Dis 2001; 32: 851-4.

19.- Gross P A, Barret T L, Dellinger P, Krause P J, Martone W J, McGowan J E Jr, et al. Purpose of quality standards for infectious diseases. Clin Infect Dis 1994; 18: 421-7.

20.- Guillemot D, Maison P, Carbon C, Balkau B, Vauzelle-Kervroëdan F, Sermet C, et al. Trends in antimicrobial use in the community-France, 1981-1992. J Infect Dis 1998; 177: 492-7.

21.- Polk R. Optimal use of modern antibiotics: emerging trends. Clin Infect Dis 1999; 29: 26474.

22.- Okeke I, Lamikanra A, Edelman R. Socioeconomic and behavioral factors leading to acquired bacterial resistance to antibiotic in developing countries. Emerg Infect Dis 1999; 5: 18-27.

23.- Marrie T, Lau C, Wheeler S, Wong C J, Feagan B G. Predictors of symptom resolution in patients with community-acquired pneumonia. Clin Infect Dis 2000; 31: 1362-7.

24.- Metlay J P, Atlas S J, Borowsky L H, Singer D E. Time course of symptom resolution in patients with community-acquired pneumonia. Respir Med 1998; 92: 1137-42.

25.- Gonzales R, Steiner J F, Sande M A. Antibiotic prescribing for adults with colds, upper respiratory tract infections and bronchitis by ambulatory care physicians. JAMA 1997; 278: 901-4.

26.- Gonzales R, Steiner J F, Lum A, Barrett P H Jr. Decreasing antibiotic use in ambulatory practice: impact of a multidimensional intervention on the treatment of uncomplicated acute bronchitis in adults. JAMA 1999; 281: 1512-9.

27.- Wipf J E, Lipsky B A, Hirschmann J V, Boyko E J, Takasugi J, Peugeot R L, et al. Diagnosing pneumonia by physical examination: relevant or relic? Arch Intern Med 1999; 159: 1082.

28.- Metlay J P, Kapoor W N, Fine MJ. Does this patient have community-acquired pneumonia? Diagnosing pneumonia by history and physical examination. JAMA 1997; 278: 1440-5.

29.- Niederman M S, Bass J B Jr, Campbell G D, Fein A M, Grossman R F, Mandell L A, et al. American Thoracic Society guidelines for the initial management of adults with communityacquired pneumonia: diagnosis, assessment of severity, and initial antimicrobial therapy. American Thoracic Society. Medical Section of the American Lung Association. Am Rev Respir Dis 1993; 148: 1418-26.

30.- Bartlett J G, Breiman R F, Mandell L A, File T M Jr. Community-acquired pneumonia in adults: guidelines for management. Clin Infect Dis 1998; 26: 811-38.

31.- Fine M J, Auble T E, Yealy D M, Hanusa B H, Wiessfeld L A, Singer D E, et al. A prediction rule to identify low-risk patients with community-acquired pneumonia. N Engl J Med 1997; 336: 243-50.

32.- Marston B J, Lipman H B, Breiman R F. Surveillance for Legionnaires' disease: risk factors for morbidity and mortality. Arch Intern Med 1994; 154: 2417-22.

33.- Sabrià M, Pedro-Botet M L, Gómez J, Roig J, Vilaseca B, Sopena N, et al. Fluoroquinolones vs macrolides in the treatment of Legionnaires disease. Chest 2005; 128: 1401-5.

34.- Blázquez Garrido R M, Espinosa Parra F J, Alemany Francés L, Ramos Guevara R M, Sánchez-Nieto J M, Segovia Hernández M, et al.Antimicrobial chemotherapy for Legionnaires disease: levofloxacin versus macrolides. Clin Infect Dis 2005; 40: 800-6.

35.- Baddour L M, Yu V L, Klugman K P, Feldman C, Ortqvist A, Rello J, et al. Combination antibiotic therapy lowers mortality among severely ill patients with pneumococcal bacteremia. Am J Respir Crit Care Med 2004; 170: 440-4.

36.- Pachon J, Prados M D, Capote F, Cuello J A, Garnacho J, Verano A. Severe communityacquired pneumonia: etiology, prognosis and treatment. Am Rev Respir Dis 1990; 142: 369-73.

37.- Levy M, Dromer F, Brion N, Leturdu F, Carbon C. Community-acquired pneumonia: importance of initial noninvasive bacteriologic and radiographic investigations. Chest 1988; 93: 43-8.

38.- Leroy O, Santre C, Beuscart C. A 5-year study of severe community-acquired pneumonia with emphasis on prognosis in patients admitted to an ICU. Intensive Care Med 1995; 21: 24-31.

39.- Gleason P P, Meehan T P, Fine J M, Galusha D H, Fine M J. Associations between initial antimicrobial therapy and medical 
outcomes for hospitalized elderly patients with pneumonia. Arch Intern Med 1999; 159: 2562-72.

40.- Woodhead M A, Arrowsmith J, ChamberlainWebber R, Wooding S, Williams I. The value of routine microbial investigation in communityacquired pneumonia. Respir Med 1991; 85: 313-7.

41.- Benito J R, Montejo J M, Cancelo L, Zalacaín R, López L, Fernández Gil de Pareja S, et al. Community-acquired pneumonia due to Legionella pneumophila serogroup 1. Study of 97 cases] Enferm Infecc Microbiol Clin 2003; 21: 394-400.

42.- Ishida T, Hashimoto T, Arita M, Tojo Y, Tachibana H, Jinnai M. A 3-year prospective study of a urinary antigen-detection test for Streptococcus pneumoniae in communityacquired pneumonia: utility and clinical impact on the reported etiology. $\mathrm{J}$ Infect Chemother 2004; 10: 359-63.

43.- Lasocki S, Scanvic A, Le Turdu F, Restoux A, Mentec H, Bleichner G, et al.Evaluation of the Binax NOW Streptococcus pneumoniae urinary antigen assay in intensive care patients hospitalized for pneumonia. Intensive Care Med 2006; 32: 1766-72.

44.- Luna C M, Brea Folco J, Aruj P, Reboca K, Balselre C, Dosi R, et al. Pneumonia due to Legionella pneumophila. Experience gathered in a University Hospital in Buenos Aires. Medicina (B Aires) 2004; 64: 97-102.

45.- Chedid M B, Ilha Dde O, Chedid M F, Dalcin P R, Buzzetti M, Jaconi Saraina P, et al. Community-acquired pneumonia by Legionella pneumophila serogroups 1-6 in Brazil. Respir Med 2005; 99: 966-75.

46.- Lopardo G, Sturba E, Martínez ML, Roel JE, Gamba A, Biondi H, et al. Detección de infección aguda por Legionella pneumophila en pacientes con neumonía adquirida en la comunidad en la ciudad de Buenos Aires. Medicina (Buenos Aires) 2002; 62: 145-8

47.- Bates J H, Campbell G D, Barron A L, McCracken G A, Morgan P N, Moses E B, et al. Microbial etiology of acute pneumonia in hospitalized patients. Chest 1992; 101: 1005-12.

48.- Fang G D, Fine M, Orloff J, Arisumi D, Yu V L, Kapoor W, et al. New and emerging etiologies for community-acquired pneumonia with implications for therapy: a prospective multicenter study of 359 cases. Medicine 1990; 69: 307-16.

49.- Marrie T J, Durant H, Yates L. Communityacquired pneumonia requiring hospitalization: 5-year prospective study. Rev Infect Dis 1989; 11: 586-99.

50.- Fine M J, Smith M A, Carson C A, Mutha SS, Sankey S S, Weissfeld L A, et al. Prognosis and outcomes of patients with community-acquired pneumonia. JAMA 1996; 275: 134-41.

51.- Levy M, Dromer F, Brion N, Leturdu F,
Carbon C. Community-acquired pneumonia. Importance of initial noninvasive bacteriologic and radiographic investigations. Chest 1988; 93: 43-8.

52.- Bianchini H, Bantar C, Schuster M, Smayevsky J, Micucci M. Limitation of the sputum in the diagnosis of lower respiratory tract infections. Acta Bioq Latin 1991; 15: 423-8.

53.- Matta M, Buu Hoï A, Varon E, Gutmann L, Mainardi J L, et al. Impact of a positive Binax NOW/Streptococcus pneumoniae/ urinary antigen test on antibiotics policy. 18th European Congress of Clinical Microbiology and Infectious Diseases, Barcelona 2008; Abstr P1290.

54.- Díaz A, Barría P, Niederman $M$, Restrepo M I, Dreyse J, Fuentes G, et al. Etiology of community-acquired pneumonia in hospitalized patients in Chile: the increasing prevalence of respiratory viruses among classic pathogens. Chest 2007; 131: 779-87.

55.- Moreno B R, Riquelme O R. Etiology of community-acquired pneumonia in immunocompetent adults. Rev Chil Infect 2005; 22 (Suppl 1): s18-25.

56.- Luna C M, Calmaggi A, Caberloto O, Gentile J, Valentini R, Ciruzzi J, et al. Pneumonia acquired in the community. Practical guide elaborated by a committee intersocieties. Medicina (B Aires) 2003; 63: 319-43.

57.- Nicodemo A C. An open label, multicenter, non-comparative study of the efficacy and safety of oral gatifloxacin in the treatment of community-acquired pneumonia: a Brazilian study in five centers. Braz J Infect Dis 2003; 7 : 62-8.

58.- Hortal M, Ruvinsky R, Rossi A, Agudelo C I, Castaneda E, Brandileone C, et al. Impact of Streptococcus pneumoniae on pneumonia in Latin American children. SIREVA-Vigía Group. Rev Panam Salud Publica 2000; 8: 185-95.

59.- Calver A, Walsh N, Quinn P, Baran C, Lonergan V, Singh K P, et al. Dosing of amoxicillin/clavulanate given every 12 hours is as effective as dosing every 8 hours for treatment of lower respiratory tract infection. Clin Infect Dis 1997; 24: 570-4.

60.- Milano E, Mazzini A, Suárez E, Pedreira W, Failache R, Torres J. Community`s acute pneumonia. Multi-centered etiological surveyJuly 96-September 97. Arch Med Int 1998; 3: 107-11.

61.- Fine M J, Smith M A, Carson C A, Mutha S S, Sankey S S, Weissfeld L A, et al. Prognosis and outcomes of patients with community-acquired pneumonia: a meta-analysis. JAMA 1996; 275 : 134-41.

62.- Soca A, Bazet C, Battistesa S, Bono C, Elicabe M, Bentancourt S. Severe communityacquired pneumonia. Pac Crit 1999; 12: 96-107. 63.- Petitpretz P, Arvis P, Marel M, Moita J,
Urueta J; CAP5 Moxifloxacin Study Group. Oral moxifloxacin $v s$ high-dosage amoxicillin in the treatment of mild-to-moderate, communityacquired, suspected pneumococcal pneumonia in adults. Chest 2001; 119: 185-95.

64.- Lobos T, Saldías F, Cartagena C, Jover E, Álvarez M, Moreno R. Chlamydia pneumoniae in patients with acquired pneumonia in the Santiago of Chile community. Rev Med Chile 1998; 126: 1483-9.

65.- Finegold S M. Aspiration pneumonia. Rev Infect Dis 1991; 13 (Suppl 9): S737-42.

66.- Kaplan S L, Mason E O Jr. Management of infections due to antibiotic-resistant Streptococcus pneumoniae. Clin Microbiol Rev 1998; 11: 628-44.

67.- Lister P D. Multiply-resistant pneumococcus: therapeutic problems in the management of serious infections. Eur J Clin Microbiol Infect Dis 1995; 14 (Suppl 1): S18-25.

68.- Jacobs M R, Bajaksouzian S, Zilles A, Lin G, Pankuch G, Appelbaum P C. Susceptibilities of Streptococcus pneumoniae and Haemophilus influenzae to 10 oral antimicrobial agents based on pharmacodynamic parameters: 1997 U.S. surveillance study. Antimicrob Agents Chemother 1999; 43: 1901-08.

69.- Hoban D J, Doern G V, Fluit A C, RousselDelvallez, Jones R N. Worldwide prevalence of antimicrobial resistance in Streptococcus pneumoniae, Haemophilus influenzae and Moraxella catarrhalis in the SENTRY antimicrobial surveillance program, 1977-1999. Clin Infect Dis 2001; 32 (Suppl 2): S81-93.

70.- Sader H S, Gales A C, Granacher T D, Pfaller M A, Jones R N; The SENTRY Study Group (Latin America). Prevalence of antimicrobial resistance among respiratory tract isolates in Latin America: results from SENTRY antimicrobial surveillance program (1997-98). Braz J Infect Dis 2000; 4: 245-54.

71.- Jacobs M R, Appelbaum P C. Susceptibility of 1100 Streptococcus pneumoniae strains isolated in 1997 from seven Latin American and Caribbean countries. Laser Study Group. Int J Antimicrob Agents 2000; 16: 17-24.

72.- Guzmán-Blanco M, Casellas J M, Sader H S. Bacterial resistance to antimicrobial agents in Latin America. The giant is awakening. Infect Dis Clin North Am 2000; 14: 67-81.

73.- Famiglietti A, Bantar C, Casellas J M, Golas M, Gutkind G, Kovensky J, et al. Sistema Informático de Resistencia (SIR). Análisis de prevalencia del año 2000. Boletín No 153. Asoc Arg Microbiol 2002; 153: 5-8.

74.- Appelbaum P C. Resistance among Streptococcus pneumoniae: Implications for drug selection. Clin Infect Dis 2002; 34: 1613-20.

75.- Critchley I A, Thornsberry C, Piazza G, Jones M, Hickey M L, Barth A L, et al. Antimicrobial susceptibility of Streptococcus pneumoniae, Haemophilus influenzae and 
Moraxella catarrhalis collected from five centers in Brazil 1997-98. Clin Microbiol Infect 2000; 6: 178-84.

76.- Thornsberry C, Brown N P, Draghi D C, Evangelista A T, Yee Y C, Sahm D F. Antimicrobial activity among multidrugresistant Streptococcus pneumoniae isolated in the United States, 2001-2005. Postgrad Med 2008;120 (3 Suppl 1): 32-8.

77.- Sahm D F, Brown N P, Draghi D C, Evangelista A T, Yee Y C, Thornsberry C. Tracking resistance among bacterial respiratory tract pathogens: summary of findings of the TRUST Surveillance Initiative, 2001-2005. Postgrad Med 2008; 120 (3 Suppl 1): 8-15.

78.- Critchley I A, Brown S D, Traczewski M M, Tillotson G S, Janjic N. National and regional assessment of antimicrobial resistance among community-acquired respiratory tract pathogens identified in a 2005-2006 U.S. Faropenem surveillance study. Antimicrob Agents Chemother 2007; 51: 4382-9.

79.- Gravet A, Camdessoucens G, Murbach V, Barrand P, Boucher A, Boulenc A, et al. Evolution of antibiotic resistance of Streptococcus pneumoniae: results of Alsace observatory in 2005. Pathol Biol (Paris) 2007; 55: 424-8.

80.- Morrissey I, Colclough A, Northwood J. Targeted surveillance: susceptibility of Streptococcus pneumoniae isolated from community-acquired respiratory tract infections in 2003 to fluoroquinolones and other agents. Int J Antimicrob Agents 2007; 30: 345-51.

81.- Borer A, Meirson H, Peled N, Porat N, Dagan R, Fraser D, et al. Antibiotic-resistant pneumococci carried by young children do not appear to disseminate to adult members of a closed community. Clin Infect Dis 2001; 33: 436-44.

82.- Heffelfinger J D, Dowell S F, Jorgensen J H, Klugman K P, Mabry L R, Musher D M, et al. Management of community-acquired pneumonia in the era of pneumococcal resistance: a report from the Drug-Resistant Streptococcus pneumoniae Therapeutic Working Group. Arch Intern Med 2000; 160: 1399-408.

83.- Performance Standards for Antimicrobial Susceptibility Testing; Nineteenth Informational Supplement. January 2009. M100-S19; Vol 29 No. 3: 72-5.

84.- Bagnulo H, Laserra J, Piñeyro L, Kubin R, Mc Givern J, Bobbaers H, et al. An open noncomparative study of the efficacy and tolerance of azithromycin in the treatment of patients with acute lower respiratory tract infections. Arch Med Int 1996; 1: 47-51.

85.- Finch R, Schürmann D, Collins O, Kubin R, Mc Givern J, Bobbaers H, et al. Randomized controlled trial of sequential intravenous (i.v.) and oral moxifloxacin compared with sequential i.v. and oral co-amoxiclav with or without clarithromycin in patients with communityacquired pneumonia requiring initial parenteral treatment. Antimicrob Agents Chemother 2002; 46: 1746-54.

86.- Garau J, Twynholm M, García-Méndez E, Siquier B, Rivero A; 557 Clinical Study Group. Oral pharmacokinetically enhanced coamoxiclav 2000/125 mg, twice daily, compared with co-amoxiclav $875 / 125 \mathrm{mg}$, three times daily, in the treatment of community-acquired pneumonia in European adults J Antimicrob Chemother 2003; 52: 826-36.

87.- File T M Jr, Lode H, Kurz H, Kozak R, Xie H, Berkowitz E, et al. Double-blind, randomized study of the efficacy and safety of oral pharmacokinetically enhanced amoxicillinclavulanate (2,000/125 milligrams) versus those of amoxicillin-clavulanate (875/125 milligrams), both given twice daily for 7 days, in treatment of bacterial community-acquired pneumonia in adults Antimicrob Agents Chemother 2004, 48: 3323-31.

88.- Siquier1 B, Sánchez-Álvarez J, GarcíaMéndez E, Sabriá M, Santos J, Pallarés R, et al. Efficacy and safety of twice-daily pharmacokinetically enhanced amoxicillin/ clavulanate $(2000 / 125 \mathrm{mg})$ in the treatment of adults with community-acquired pneumonia in a country with a high prevalence of penicillinresistant Streptococcus pneumoniae. J Antimicrob Chemother 2006;57: 536-45.

89.- Jasovich A, Curcio D, Prieto S, Bustos J, Mastruzzo M, Tosello C, et al. Frecuencia de Streptococcus pneumoniae penicilina-resistente (SpR) en adultos con neumonía adquirida en la comunidad (NAC): racionalidad de los esquemas terapéuticos empíricos basados en los sistemas de vigilancia de resistencia bacteriana. $X$ Congreso Panamericano de Infectología. Guadalajara, México 2001, Abstr 59.

90.- File T M, Jr. Appropriate use of antimicrobials for drug-resistant pneumonia: focus on the significance of $\beta$-lactam-resistant Streptococcus pneumoniae. Clin Infect Dis 2002; 34: S17-S26.

91.- Aspa J, Rajas O, Rodríguez de Castro F. Drug-resistant pneumococcal pneumonia: clinical relevance and related factors. Clin Infect Dis 2004; 38: 787-98.

92.- File T M Jr, Tan J S, Boex J R. The clinical relevance of penicillin-resistant Streptococcus pneumoniae: a new perspective. Clin Infect Dis 2006; 42: 798-800.

93.- Karstaedt A S, Khoosal M, Crewe-Brown H H. Pneumococcal bacteremia in adults in Soweto, South Africa, during the course of a decade. Clin Infect Dis 2001; 33: 610-14.

94.- Mandell L, Wunderink R, Anzueto A, Bartlett J G, Campbell G D, Dean N C, et al. Infectious Diseases Society of America/ American Thoracic Society Consensus Guidelines on the Management of Community-
Acquired Pneumonia in Adults. Clin Infect Dis 2007; 44: S27-72.

95.- Artiles F, Horcajada-Herrera I, Noguera-Catalán J, Alamo-Antúnez I, Bordes-Benítez A, Lafarga-Capuz B: Macrolide-resistant Streptococcus pneumoniae on the islands of Gran Canaria and Lanzarote (Spain): molecular mechanisms and serogroup relationships. Enferm Infecc Microbiol Clin 2007; 25: 570-5.

96.- Wierzbowski A K, Nichol K, Laing N, Hisanaga T, Nikulin A, Karlowsky J A, et al. Macrolide resistance mechanisms among Streptococcus pneumoniae isolated over 6 years of Canadian Respiratory Organism Susceptibility Study (CROSS) (1998 2004). J Antimicrob Chemother 2007; 60: 733-40.

97.- Hoban D J, Zhanel G G. Clinical implications of macrolide resistance in community-acquired respiratory tract infections. Expert Rev Anti Infect Ther 2006; 4: 973-80.

98.- Reyes J, Hidalgo M, Díaz L, Rincón S, Moreno J, Vanegas N, et al. Characterization of macrolide resistance in Gram-positive cocci from Colombian hospitals: a countrywide surveillance. Int J Infect Dis 2007; 11: 329-36.

99.- Bonofiglio L, Ojeda M I, de Mier C, Vay C, Famiglietti A, Gutkind G, et al. Phenotypic and genotypic characterization of macrolide resistant Streptococcus pneumoniae recovered from adult patients with community-acquired pneumonia in an Argentinian teaching hospital. Int J Antimicrob Agents 2005; 25: 260-3

100.-Smayevsky J, López H, Di Chiara M, Scarano S, Lanza A, Vilches V, et al. Activity of gatifloxacin compared to those of seven agents against bacteria recovered from outpatients with respiratory tract infection. Diag Microbiol Infect Dis 2000; 37: 261-4.

101.-Pihlajamäki M, Kotilainen P, Kaurila T. Macrolide-resistant Streptococcus pneumoniae and use of antimicrobial agents. Clin Infect Dis 2001; 33: 483-8

102.-Stephens D S, Zughaier S M, Whitney C G, Baughman W S, Barker L, Gay K, et al. Incidence of macrolide resistance in Streptococcus pneumoniae after introduction of the pneumococcal conjugate vaccine: population-based assessment. Lancet 2005; 365: 855-63.

103.-Lonks J R, Garau J, Gómez L, Xercavins M, Ochoa de Echagüen A, Gareen IF, et al. Failure of macrolide antibiotic treatment in patients with bacteremia due to erythromycin-resistant Streptococcus pneumoniae. Clin Infect Dis 2002; 35: 556-64.

104.-Klugman K P. Editorial commentary: antibiotic selection of multiply resistant pneumococci. Clin Infect Dis 2001; 33: 489-91.

105.-Daneman N, Low D E, McGeer A, Green K A, Fisman D N. At the threshold: defining clinically meaningful resistance 
thresholds for antibiotic choice in communityacquired pneumonia. Clin Infect Dis 2008; 46: 1131-8.

106.-Chen D K, Mcgeer A, De Azavedo J C, Low D E. Decreased susceptibility of Streptococcus pneumoniae to fluoroquinolones in Canada. N Engl J Med 1999; 341: 233-9.

107.-Ho P L, Que T L, Tsang D N, Ng T K, Chow K H, Seto W H. Emergence of fluoroquinolone resistance among multiply resistant strains of Streptococcus pneumoniae in Hong Kong. Antimicrob Agents Chemother 1999; 43: 1310-3.

108.-Wise R, Brenwald N, Gill M, Fraise A. Streptococcus pneumoniae resistance to fluoroquinolones. Lancet 1996; 348: 1660.

109.-Goldsmith C E, Moore J E, Murphy P C, Ambler J E. Increased incidence of ciprofloxacin resistance in penicillin-resistant pneumococci in Northern Ireland. J Antimicrob Chemother 1998; 41: 420-1.

110.-Ho P L, Tse W S, Tsang K W, Kwok T K, $\mathrm{Ng} \mathrm{T}$ K, Cheng V C, et al. Risk factors for acquisition of levofloxacin-resistant Streptococcus pneumoniae: a case-control study. Clin Infect Dis 2001; 32: 701-7.

111.- Weiss K, Restieri C, Gauthier R. A nosocomial outbreak of fluoroquinolone-resistant Streptococcus pneumoniae. Clin Infect Dis 2001; 33: 517-22.

112.-Rittenhouse S F, Miller L A, Kaplan R L, Mosely GH, Poupard J A. A survey of betalactamase-producing Haemophilus influenzae. An evaluation of 5750 isolates. Diagn Microbiol Infect Dis 1995; 21: 223-5.

113.-Jones R N, Jacobs M R, Washington J A, Pfaller M A. A 1994-95 survey of Haemophilus influenzae susceptibility to ten orally administered agents. A 187 clinical laboratory center sample in the United States. Diagn Microbiol Infect Dis 1997; 27: 75-83.

114.-Casellas J M. Epidemiology of bacterial incidence and resistance in community acquired respiratory tract infection in South America. $9^{\text {th }}$ International Congress on Infectious Disease. Buenos Aires 2000; Abstr. 3.002.

115.-Liapikou A, Ferrer M, Polverino E, Balasso V, Esperatti M, Piñer R, et al. Severe Community-acquired pneumonia: Validation of the Infectious Diseases Society of America/ American Thoracic Society Guidelines to Predict an Intensive Care Unit Admission. Clin Infect Dis 2009; 48: 377-85.

116.-Angus D C, Marrie T J, Obrosky D S, Clermont G, Dremsizov T T, Coley C, et al. Severe community-acquired pneumonia: use of intensive care services and evaluation of American and British Thoracic Society Diagnostic criteria. Am J Respir Crit Care Med 2002; 166: 717-23.

117.-Valencia M, Badia J R, Cavalcanti M, Ferrer M, Agusti C, Angrill J, et al. Pneumonia severity index class $\mathrm{v}$ patients with community-acquired pneumonia: characteristics, outcomes, and value of severity scores. Chest 2007; 132: 515-22.

118.-Kauppinen M T, Herva E, Kujala P, Leinonen M, Saikku P, Syriälä H. The etiology of community-acquired pneumonia among hospitalized patients during a Chlamydia pneumoniae epidemic in Finland. J Infect Dis 1995; 172: 1330-5.

119.-Neill A M, Martín J R, Weir R, Anderson R, Cherevshsky A, Epton M J, et al. Communityacquired pneumonia: aetiology and usefulness of severity criteria on admission. Thorax 1996; 51: 1010-6.

120.-Lim W S, van der Eerden M M, Laing R, Boersma W G, Karalus N, Town G I, et al. Defining community acquired pneumonia severity on presentation to hospital: an international derivation and validation study. Thorax 2003; 58: 377-82.

121.-Fine M J, Auble T E, Yealy D M, Hanusa B H, Wiessfeld L A, Singer D E, et al. A prediction rule to identify low-risk patients with community-acquired pneumonia. N Engl J Med 1997; 336: 243-50

122.-British Thoracic Society, Myint P K, Kamath A V, Vowler S L, Maisey D N, Harrison B D: Severity assessment criteria recommended by the British Thoracic Society (BTS) for community-acquired pneumonia (CAP) and older patients. Should SOAR (systolic blood pressure, oxygenation, age and respiratory rate) criteria be used in older people? A compilation study of two prospective cohorts. Age Ageing 2006; 35: 286-91.

123.-Charles P G, Wolfe R, Whitby M, Fuller A J, Stirling R, Wright A A, et al. SMARTCOP: a tool for predicting the need for intensive respiratory or vasopressor support in community-acquired pneumonia. Clin Infect Dis 2008; 47: 375-84.

124.-Challen K, Bright J, Bentley A, Walter D. Physiological-social score (PMEWS) vs CURB-65 to triage pandemic influenza: a comparative validation study using communityacquired pneumonia as a proxy. BMC Health Serv Res 2007; 7: 33.

125.-Fine M J, Hough L J, Medsger A R, Li Y H, Ricci E M, Singer D E, et al. The hospital admission decision for patients with community-acquired pneumonia: results from the pneumonia Patient Outcomes Research Team cohort study. Arch Intern Med 1997; 157: 36-44.

126.-Fine M J, Medsger A R, Stone R A, Marrie T J, Coley C M, Singer D E, et al. The hospital discharge decision for patients with communityacquired pneumonia. Results from the pneumonia Patient Outcomes Research Team cohort study. Arch Intern Med 1997; 157: $47-$ 56.

127.-Marrie T J, Lau C Y, Wheeler S L, Wong C J,
Vandervoot M K, Feagan B G. A controlled trial of a critical pathway for treatment of community-acquired pneumonia. CAPITAL Study Investigators. Community-acquired pneumonia intervention trial assessing levofloxacin. JAMA 2000; 283: 749-55.

128.-Renaud B, Coma E, Labarere J, Hayon J, Roy P M, Boureaux H, et al. Routine use of the Pneumonia Severity Index for guiding the site-of-treatment decision of patients with pneumonia in the emergency department: a multicenter, prospective, observational, controlled cohort study. Clin Infect Dis 2007; 44: 41-9.

129.-Labarere J, Stone R, Obrosky D, Yealy D M, Meehan T P, Fine J M, et al. Comparison of outcomes for low-risk outpatients and inpatients with pneumonia Chest 2007 131: 480-8

130.-Ananda-Rajah M R, Charles P G, Melvani S, Burrell L L, Johnson P D, Grayson M L. Comparing the pneumonia severity index with CURB-65 in patients admitted with community acquired pneumonia. Scand J Infect Dis 2008; 40: 293-300.

131.-Rello J, Rodríguez A. Severity of illness assessment for managing community-acquired pneumonia. Intensive Care Med 2007; 33: $2043-$ 4.

132.-Rosón B, Carratalá J, Dorca J, Casanova A, Manresa F, Gudiol F. Etiology, reasons for hospitalization, risk classess, and outcomes of community-acquired pneumonia in patients hospitalized on the basis of conventional admission criteria. Clin Infect Dis 2001; 33: $158-65$.

133.-Woodhead M, Blasi F, Ewig S, Huchon G, Ieven M, Ortqvist A, et al. Guidelines for the management of adult lower respiratory tract infections. Eur Respir J 2005; 26: 1138-80.

134.-Mundy L M, Oldach D, Auwaerter P G, Gaydos C A, Moore R D, Bartlett J G, et al. Implications for macrolide treatment in community-acquired pneumonia. Hopkins CAP Team. Chest 1998; 113: 1201-6.

135.-Aubier M, Verster R, Regamey C, Geslin P, Vercken J B. Once-daily sparfloxacin versus high-dosage amoxicillin in the treatment of community-acquired, suspected pneumococcal pneumonia in adults. Clin Infect Dis 1998; 26 : 1312-20.

136.-O’Doherty B, Dutchman D A, Pettit R, Maroli A. Randomized, double-blind, comparative study of grepafloxacin and amoxycillin in the treatment of patients with community-acquired pneumonia. J Antimicrob Chemother 1997; 40 (Suppl A): 73-81.

137.-Tremolieres F, de Kock F, Pluck N, Daniel R. Trovafloxacin versus high-dose amoxicillin ( $1 \mathrm{~g}$ three times daily) in the treatment of community-acquired bacterial pneumonia Eur J Clin Microbiol Infect Dis 1998; 17: 447-53. 
138.-Johnson D M, Stilwell M G, Fritsche T R, Jones R N; Emergence of multidrug-resistant Streptococcus pneumoniae: report from the SENTRY Antimicrobial Surveillance Program (1999-2003). Diagn Microbiol Infect Dis 2006; 56: 69-74.

139.-Castanheira M, Gales A C, Mendes R E, Jones R N, Sader H S. Antimicrobial susceptibility of Streptococcus pneumoniae in Latin America: results from five years of the SENTRY Antimicrobial Surveillance Program. Clin Microbiol Infect 2004; 10 (7): 645-51.

140.-Ramírez J, Unowsky J, Talbot G H, Zhang H, Townsend L. Sparfloxacin versus clarithromycin in the treatment of community-acquired pneumonia. Clin Ther 1999; 21: 103-17.

141.-Patel T, Desai R, Duff J, Johnson M E, Breisch S A, Maroli A N. Comparison of grepafloxacin (GFX) with clarithromycin (CLA) in the treatment of community-acquired pneumonia (CAP) [abstract LM-69]. In: Program and abstracts of the $37^{\text {th }}$ International Conference on Antimicrobial Agents and Chemotherapy. Washington, DC: American Society for Microbiology, 1997, page 378.

142.-Moola S, Hagberg L, Churchyard G A, Dylewski J S, Sedani S, Staley H, et al. Comparison of grepafloxacin with clarithromycin in the treatment of communityacquired pneumonia (CAP). Chest 1999; 116 : 974-983.

143.-Sullivan J, Gezon J, Williams-Hopkins D, and the Trovan Community Pneumonia Study Group. A double blind, randomized multicenter study in ambulatory community-acquired pneumonia (CAP) comparing trovafloxacin with clarithromycin [abstract LM-73]. In: Program and abstracts of the $37^{\text {th }}$ International Conference on Antimicrobial Agents and Chemotherapy. Washington, DC: American Society for Microbiology, 1997. Abstr. LM 73 page 378.

144.-Fogarty C, Grossman C, Williams J, Haverstock D, Church D. Efficacy and safety of moxifloxacin vs clarithromycin for community-acquired pneumonia. Infect Med 1999; 16: 748-63.

145.-Ortqvist A, Valtonen M, Cars O, Wahl M, Saikku P, Jean C; Oral empiric treatment of community-acquired pneumonia: a multicenter, double-blind, randomized study comparing sparfloxacin with roxithromycin. Chest 1996; 110: 1499-506.

146.-Bantar C, Nicola F, Fernández Canigia L, Arenoso H J, Soutric C, Montoto M, et al. A pharmacodynamic model to support a twelvehour dosing interval for amoxicillin/sulbactam, a novel oral combination, in the treatment of community-acquired lower respiratory tract infections. J Chemother 2000; 12: 223-27.

147.-Bantar C, Nicola F, Fernández Canigia L, Arenoso H J, Soutric J, Montoto M, et al. Rationale for treating community-acquired lower respiratory tract infections with amoxicillin/sulbactam combination through a pharmacodynamic analysis in the setting of aminopenicillin-resistant organisms. J Chemother 2001; 13: 402-6.

148.-Drusano G L, Craig W A. Relevance of pharmacokinetics and pharmacodynamics in the selection of antibiotics for respiratory tract infections. J Chemother 1997; 3: 38-44.

149.-Carbon C, members of the International Study Group. Comparative study of levofloxacin (LVFX) and co-amoxiclav (C0-AC) in the treatment of community-acquired pneumonia (CAP) in adults [abstract LM-70]. In: Program and abstracts of the $37^{\text {th }}$ International Conference on Antimicrobial Agents and Chemotherapy. Washington, DC: American Society for Microbiology, 1997.

150.-Saito A, Soejima R. The first comparative study with levofloxacin: a double-blind comparative study of gatifloxacin, a new quinolone, and levofloxacin in pneumonia [abstract L-101]. In: Program and abstracts of the $38^{\text {th }}$ International Conference on Antimicrobial Agents and Chemotherapy. Washington, DC: American Society for Microbiology, 1998.

151.-Kelley M A, Weber D J, Gilligan P, Cohen M S. Breakthrough pneumococcal bacteremia in patients being treated with azithromycin and clarithromycin. Clin Infect Dis 2000; 31: 1008-11.

152.-Lisby G, Brasholt M S, Teglbjerg M S. Bacteremia and meningitis caused by a macrolide-sensitive strain of Streptococcus pneumoniae during treatment with azithromycin. Clin Infect Dis 2001; 33: 415-6.

153.-Lode H, Garau J, Grassi C, Hosie J, Huchon $\mathrm{G}$, Legakis N, et al. Treatment of communityacquired pneumonia: a randomized comparison of sparfloxacin, amoxycillin-clavulanic acid and erythromycin. Eur Respir J 1995; 8: 1999-2007.

154.-Phillips S L, Branaman-Phillips J. The use of intramuscular cefoperazone versus intramuscular ceftriaxone in patients with nursing home-acquired pneumonia. J Am Geriatr Soc 1993; 41: 1071-4.

155.-Ortiz-Ruiz G, Caballero-López J, Friedland I R, Woods G L, Carides A; Protocol 018 Ertapenem Community-Acquired Pneumonia Study Group. A study evaluating the efficacy, safety, and tolerability of ertapenem versus ceftriaxone for the treatment of community-acquired pneumonia in adults. Clin Infect Dis 2002; 34 : 1076-83.

156.-Poirier R, Chardon H, Beraud A, Debieuvre D, Petitprez P, Montestruc F, et al. Efficacy and tolerability of pristinamycin $v s$ amoxicillinclavulanic acid combination in the treatment of acute community-acquired pneumonia in hospitalized adults. Rev Pneumol Clin 1997; 53: 325-31.

157.-Rosón B, Carratalá J, Tubau F, Dorca J,
Linares J, Pallares R, et al. Usefulness of betalactam therapy for community-acquired pneumonia in the era of drug-resistant Streptococcus pneumoniae: a randomized study of amoxicillin-clavulanate and ceftriaxone. Microb Drug Resist 2001; 7: 85-96.

158.-Pena C, Pujol M, Ardanuy C, Ricart A, Pallares R, Linares J, et al. Epidemiology and successful control of a large outbreak due to Klebsiella pneumoniae producing extendedspectrum beta-lactamases. Antimicrob Agents Chemother 1998; 42: 53-8.

159.-Bantar C, Famiglietti A, Goldberg M, The Antimicrobial Committee and The National Surveillance Program (SIR) Participants Group. Three-year surveillance study of nosocomial bacterial resistance in Argentina. Int J Infect Dis 2000; 4: 85-90.

160.-Sader H S, Gales A C, Pfaller M A, Mendes R E, Zoccoli C, Barth A, et al. Pathogen frequency and resistance patterns in Brazilian hospitals: summary of results from three years of the SENTRY Antimicrobial Surveillance Program. Braz J Infect Dis 2001; 5: 200-14.

161.-Bantar C, Famiglietti A, Radice M, Quinteros M. A 7-year national survey on bacterial resistance in bronchoalveolar lavage from patients hospitalized in Argentina. Diagn Microbiol Infect Dis 2008; 60: 65-9.

162.-Sader H S, Jones R N, Gales A C, Silva J B, Pignatari A C. SENTRY antimicrobial surveillance program report: Latin American and Brazilian results for 1997 through 2001. Braz J Infect Dis 2004; 8: 25-79.

163.-Bantar C, Sartori B, Vesco E, Heft C, Saúl M, Salamone F, et al. A hospitalwide intervention program to optimize the quality of antibiotic use: impact on prescribing practice, antibiotic consumption, cost savings, and bacterial resistance. Clin Infect Dis 2003; 37 : 180-6.

164.-Williams D, Perri M, Zervos M J. Randomized comparative trial with ampicillin/sulbactam versus cefamandole in the therapy of community acquired pneumonia. Eur J Clin Microbiol Infect Dis 1994; 13: 293-8.

165.-Stein G E, Mantz S L. Antibiotic utilization and cost analysis in hospitalized patients with community-acquired pneumonia. Hosp Pharm 1995; 30: 132-4.

166.-Fogarty C, Dowell M E, Ellison W T, Vrooman P S, Jr, White B J, Mayer H. Treating community-acquired pneumonia in hospitalized patients: gatifloxacin $v s$ ceftriaxone/ clarithromycin. J Resp Dis 1999; 20 (Suppl): S60-S69.

167.-Norrby S R, Petermann W, Willcox P A, Vetter N, Salewski E. A comparative study of levofloxacin and ceftriaxone in the treatment of hospitalized patients with pneumonia. Scand J Infect Dis 1998; 30: 397-404. 
168.-Nathwani D. Place of parenteral cephalosporins in the ambulatory setting: clinical evidence. Drugs 2000; 59 Suppl 3: 37-46.

169.-Bagnulo H, Fortunato C, Villardino S, Esmoris G, Vignolo G. Home management of community-acquired pneumonia: an Uruguayan experience. $9^{\text {th }}$ International Congress on Infectious Diseases. Buenos Aires, Argentina 2000, Abstr 70.002.

170.-Plouffe J F. Importance of atypical pathogens of community-acquired pneumonia. Clin Infect Dis 2000; 31 (Suppl 2): S35-9.

171.-Stahl J E, Barza M, DesJardin J, Martin R, Eckman M H. Effect of macrolides as part of initial empiric therapy on length of stay in patients hospitalized with community-acquired pneumonia. Arch Intern Med 1999 Nov 22; 159 (21): 2576-80.

172.-Tan J S, File T M Jr, Di Persio J R, DiPersio L P, Hamor R, Saravolatz L D, et al. Persistently positive culture results in a patient with community-acquired pneumonia due to Legionella pneumophila. Clin Infect Dis 2001; 32 (11): 1562-6.

173.-Hohl P, Buser U, Frei R. Fatal Legionella pneumophila pneumonia: treatment failure despite early sequential oral-parenteral amoxicillin-clavulanic acid therapy. Infection 1992; 20: 99-100.

174.-Ma X X, Galiana A, Pedreira W, Mowszowicz M, Christophersen I, Machiavello S, et al. Community-acquired methicillin-resistant Staphylococcus aureus, Uruguay. Emerg Infect Dis 2005; 11 (6): 973-6.

175.-Paganini H, Della Latta M P, Muller Opet B, Ezcurra G, Uranga M, Aguirre C, et al. Community-acquired methicillin-resistant Staphylococcus aureus infections in children: multicenter trial. Arch Argent Pediatr 2008 Oct; 106 (5): 397-403.

176.-Curcio D, Fernández F, Cané A, Barcelona L, Stamboulian D. Indications of a new antibiotic in clinical practice: results of the tigecycline initial use registry. Braz J Infect Dis 2008;12 (3): 198-201

177.-Munoz-Price L S, Lolans K, Quinn J P. Four cases of invasive methicillin-resistant Staphylococcus aureus (MRSA) infections treated with tigecycline. Scand J Infect Dis 2006; 38 (11-12): 1081-4.

178.-Florescu I, Beuran M, Dimov R, Razbadauskas A, Bochan M, Fichev G, et al. Efficacy and safety of tigecycline compared with vancomycin or linezolid for treatment of serious infections with methicillinresistant Staphylococcus aureus or vancomycinresistant enterococci: a Phase 3, multicentre, double-blind, randomized study. J Antimicrob Chemother 2008; 62 Suppl 1: i17-28.

179.-de Klerk G J, van Steijn J H, Lobatto S, Jaspers C A, van Veldhuizen W C, Hensing $\mathrm{C} \mathrm{A}$, et al. A randomised, multicentre study of ceftriaxone versus standard therapy in the treatment of lower respiratory tract infections. Int J Antimicrob Agents 1999; 12 : 121-7.

180.-Reingold A L. Role of Legionellae in acute infections of lower respiratory tract. Rev Infect Dis 1988; 10: 1018-28.

181.-Ruiz M, Ewig S, Torres A, Arancibia F, Marco F, Mensa J, et al. Severe communityacquired pneumonia: risk factors and follow-up epidemiology. Am J Respir Crit Care Med 1999; 160: 923-9.

182.-Zhanel G G, Ennis K, Vercaigne L, Walkty A, Gin A S, Embil J, et al. A critical review of the fluoroquinolones: focus on respiratory infections. Drugs 2002; 62: 13-59.

183.-Arnold F W, Summersgill J T, Lajoie A S, Peyrani P, Marrie T J, Rossi P, et al. A worldwide perspective of atypical pathogens in community-acquired pneumonia. Am J Respir Crit Care Med 2007; 175:1086-93.

184.-Rodríguez A, Mendia A, Sirvent J M, Barcenilla F, de la Torre-Prados M V, Solé-Violán J, et al. Combination antibiotic therapy improves survival in patients with community-acquired pneumonia and shock. Crit Care Med 2007; 35 (6): 1493-8.

185.-Mykietiuk A, Carratalà J, Fernández-Sabé N, Dorca J, Verdaguer R, Manresa F, et al. Clinical outcomes for hospitalized patients with Legionella pneumonia in the antigenuria era: the influence of levofloxacin therapy. Clin Infect Dis 2005; 40: 794-9.

186.- Johnson C C, Livornese L, Gold M J, Pitsakis P G, Taylor S, Levinson M E. Activity of cefepime against ceftazidime-resistant gram-negative bacilli using low and high inocula. Antimicrob Agents Chemother 1995; 35: 765-73.

187.-Patterson J E, Hardin T C, Kelly M T, Jorgensen J H. Association of antibiotic utilization measures and control of multipledrug resistance in Klebsiella pneumoniae. Infect Control Hosp Epidemiol 2000; 21: 455-8.

188.-Zervos M, Nelson M, and the Cefepime Study Group. Cefepime versus ceftriaxone for empiric treatment of hospitalized patients with community-acquired pneumonia. Antimicrob Agents Chemother 1998; 42: 729-33.

189.-Speich R, Imhof E, Vogt M, Grossenbacher M, Zimmerli W. Efficacy, safety, and tolerance of piperacillin/tazobactam compared to co-amoxiclav plus an aminoglycoside in the treatment of severe pneumonia. Eur J Clin Microbiol Infect Dis 1998; 17: 313-7.

190.-Bantar C, Di Chiara M, Nicola F, Relloso S, Smayevsky J. Comparative in vitro bactericidal activity between cefepime and ceftazidime, alone and associated with amikacin, against carbapenem-resistant Pseudomonas aeruginosa strains. Diag Microbiol Infect Dis 2000; 37 : 41-4.

191.-Visalli M A, Jacobs M R, Appelbaum P C.
Determination of activities of levofloxacin, alone and combined with gentamicin, ceftazidime, cefpirome and meropenem against 124 strains of Pseudomonas aeruginosa by checkerboard and time-killing methodology. Antimicrob Agents Chemother 1998; 42: 953-5.

192.-Gerceker A A, Gurler B. In-vitro activities of various antibiotics, alone and in combination with amikacin against Pseudomonas aeruginosa. J Antimicrob Chemother 1995; 36: 707 11.

193.-Castanheira M, Jones R N, Livermore D M. Antimicrobial activities of doripenem and other carbapenems against Pseudomonas aeruginosa, other nonfermentative bacilli, and Aeromonas spp. Diag Microbiol Infect Dis 2009; doi:10.1016/j.diagmicrobio.2009.01.026.

194.-Feagan B G. A controlled trial of a critical pathway for treating community-acquired pneumonia: the CAPITAL study. Communityacquired pneumonia intervention trial assessing levofloxacin. Pharmacotherapy 2001; 21 (7 pt 2): $89 \mathrm{~s}-94 \mathrm{~s}$.

195.-Milkovich G. Intravenous-to-oral transition therapy in community-acquired pneumonia: the INOVA Health System experience. Pharmacotherapy 2001; 21 (7 Pt 2): 83S-88S.

196.-Hirata-Dulas C A, Stein D J, Guay D R, Gruninger R P, Peterson P K. A randomized study of ciprofloxacin versus ceftriaxone in the treatment of nursing home-acquired lower respiratory tract infections. J Am Geriatr Soc 1991; 39: 979-85.

197.-Siegel R E, Halpen N A, Almenoll P N, Lee A, Cashin R, Greene J G. A prospective randomized study of inpatient i.v. antibiotics for community-acquired pneumonia: the optimal duration of therapy. Chest 1996; 110: 965-71.

198.-Chan R, Hemeryck L, O’Regan M, Clancy L, Feely J. Oral versus intravenous antibiotics for community-acquired lower respiratory tract infection in a general hospital: open, randomized, controlled trial. Br J Med 1995; 310: 360-2.

199.-Dresser L D, Niederman M S, Paladino J A. Cost-effectiveness of gatifloxacin $v s$ ceftriaxone with a macrolide for the treatment of community-acquired pneumonia. Chest 2001; 119: 1439-48.

200.-Dowell S F. The best treatment for pneumonia. Arch Inter Med 1999; 159: 2511-12.

201.-Christensen D, Feldman C, Rossi P, Marrie T, Blasi F, Luna C, et al. HIV infection does not influence clinical outcomes in hospitalized patients with bacterial community-acquired pneumonia: results from the CAPO international cohort study. Clin Infect Dis 2005; 41:554-6.

202.-Davison R, Cavalcanti R, Brunton J L, Bast D J, de Azavedo J C, Kibsey P, et al. Resistance to levofloxacin and failure of treatment of pneumococcal pneumonia. N Engl 
J Med 2002; 346: 747-50.

203.-Fuller J D, Low D E. A review of Streptococcus pneumoniae infection treatment failures associated with fluoroquinolone resistance. Clin Infect Dis 2005; 41: 118-21.

204.-Marik P E. Aspiration pneumonitis and aspiration pneumonia. N Eng J Med 2001; 344 : 665-71.

205.-Mier L, Dreyfuss D, Darchy B, Lanore J J, Djedaïni $\mathrm{K}$, Weber $\mathrm{P}$, et al. Is penicillin $\mathrm{G}$ an adequate initial treatment for aspiration pneumonia? A prospective evaluation using a protected specimen brush and quantitative cultures. Intensive Care Med 1993; 19: 279-84.

206.-Marik P E, Careau P. The role of anaerobes in patients with ventilator-associated pneumonia and aspiration pneumonia: a prospective study. Chest 1999; 115: 178-83.

207.-Levinson M E, Mangura C T, Lorber B, Abrutyn E, Pesanti E L, Levy R S, et al. Clindamycin compared with penicillin for the treatment of lung abscess. Ann Intern Med 1983; 98: 466-71.

208.-Gudiol F, Manressa C T, Pallares R, Dorca J, Rufi G, Boada J, et al. Clindamycin vs penicillin for anaerobic lung infections: high rate of penicillin failures associated with penicillinresistant Bacteroides melaninogenicus. Arch Inter Med 1990; 150: 2525-9.

209.-Germaud P, Potrier J, Jacqueme P, Guerin J C, Benard Y, Boutin C, et al. Monotherapy using amoxicillin/clavulanic acid as treatment of first choice in community-acquired lung abscess. Rev Pneumol Clin 1993; 49: 137-41.

210.-Saldias F, Flores L J, Torres C, García P, Díaz A. Susceptibilidad a antimicrobianos de Streptococcus pneumoniae en población infantil y adulta de Santiago: Período 1997-2003. Rev Med Chile 2005; 133: 42-9. 


\begin{tabular}{|c|c|} 
Cuadro 1. Fuerza de la evidencia científica que respaldan las recomendaciones de \\
ConsenSur II (año 2009). Modificadas de Gross y cols
\end{tabular}

\begin{tabular}{|c|c|}
\hline Item & Recomendación y grado de evidencia \\
\hline \multirow[t]{3}{*}{ De la Rx de tórax } & $\begin{array}{l}\text { A los pacientes con tos productiva, falta de aire, crepitaciones en la auscultación, con o sin evidencia de } \\
\text { fiebre o dolor torácico, se les debe efectuar una radiografía de tórax (II) }\end{array}$ \\
\hline & $\begin{array}{l}\text { A los pacientes con tos productiva, falta de aire, crepitaciones en la auscultación, con o sin evidencia de } \\
\text { fiebre o dolor torácico, se les debe efectuar una radiografía de tórax (II) }\end{array}$ \\
\hline & Si en ella se evidencian nuevos infiltrados, estos pacientes deben considerarse afectados por una NAC (I) \\
\hline \multirow[t]{2}{*}{ Pruebas de laboratorio general } & $\begin{array}{l}\text { Las pruebas de laboratorio de rutina pueden ser innecesarias en pacientes bajo } 50 \text { años de edad sin ante- } \\
\text { cedentes de enfermedades neoplásicas, cerebrovasculares, renales o hepáticas, insuficiencia cardíaca con- } \\
\text { gestiva, diabetes mellitus y en ausencia de: estado mental alterado, pulso } \geq 125 / \mathrm{pm} \text {, frecuencia respiratoria } \\
\geq 30 \text { respiraciones/minuto, presión arterial sistólica }<90 \mathrm{mmHg} \text { y temperatura }<35^{\circ} \mathrm{C} 0 \geq 40^{\circ} \mathrm{C} \text { (III) }\end{array}$ \\
\hline & $\begin{array}{l}\text { De lo contrario, se les deberá efectuar un hemograma completo, evaluación renal (incluyendo medición de } \\
\text { electrolitos en suero) y hepática mínima, glicemia sérica y medición de saturación de } \mathrm{O}_{2} \text { (II) }\end{array}$ \\
\hline Serología para VIH & $\begin{array}{l}\text { Cualquier paciente sin co-morbilidades y que requiera hospitalización, se debe someter a una prueba } \\
\text { serológica para } \mathrm{VIH} \text { (III) }\end{array}$ \\
\hline Estratificación según riesgo & $\begin{array}{l}\text { Los pacientes se deben estratificar en forma subsiguiente para la clase de riesgo. El panel considera que la } \\
\text { pauta PORT es un sistema de calificación adecuado. Sin embargo, ciertas clasificaciones clínicas además } \\
\text { de la PSI podrían ser más adecuadas en la práctica clínica (por ej.: CURB-65, CRB-65) (II) }\end{array}$ \\
\hline Lugar de atención del paciente & $\begin{array}{l}\text { Luego de que el paciente es categorizado como se sugiere, se debe decidir el lugar de asistencia médica } \\
\text { en forma acorde (II) }\end{array}$ \\
\hline \multirow[t]{3}{*}{ Estudios microbiológicos } & No se recomiendan los estudios microbiológicos en pacientes que se traten en forma ambulatoria (II). \\
\hline & $\begin{array}{l}\text { A todos los pacientes que se internen en una sala clínica general o en un sitio de asistencia domiciliaria, } \\
\text { se les debe efectuar cultivo de sangre y análisis del esputo. En pacientes que ingresen a UCl, deberían } \\
\text { efectuarse pruebas a partir de muestras séricas dobles para C. pneumoniae, M. pneumoniae y antígeno } \\
\text { urinario para Legionella spp y S. pneumoniae (III) }\end{array}$ \\
\hline & $\begin{array}{l}\text { En caso de sospecha epidemiológica o clínica, como así también en pacientes con mal resultado sin expli- } \\
\text { cación, se pueden investigar otros microorganismos (II) }\end{array}$ \\
\hline
\end{tabular}




\begin{tabular}{|c|c|c|}
\hline Categoría de paciente & Esquema antimicrobiano & $\begin{array}{l}\text { Grado de } \\
\text { evidencia }\end{array}$ \\
\hline $\begin{array}{l}\text { Grupo 1a, pacientes bajo } 60 \text { años de edad sin evidencia de } \\
\text { enfermedad pulmonar obstructiva crónica (EPOC), incluyendo } \\
\text { asma, tabaquismo, alcoholismo o diabetes mellitus }\end{array}$ & Amoxicilina & (I) \\
\hline $\begin{array}{l}\text { Grupo } 1 \mathrm{~b} \text {, pacientes de } 60 \text { años de edad o mayores, que } \\
\text { presentan cualquier de los factores predisponentes mencionados } \\
\text { anteriormente }\end{array}$ & $\begin{array}{l}\text { Combinaciones de amoxicilina / inhibidor de } \\
\beta \text {-lactamasa }\end{array}$ & $(\mathrm{I}, \mathrm{II})$ \\
\hline $\begin{array}{l}\text { Grupo } 2 a \text {, pacientes que se manejarán en una sala general del } \\
\text { hospital o sala de enfermería }\end{array}$ & Aminopenicilina \pm un inhibidor de $\beta$-lactamasas & $(I, I I, I I)$ \\
\hline $\begin{array}{l}\text { Grupo } 2 b \text {, pacientes que se manejarán en el domicilio } \\
\text { (tratamiento domiciliario) }\end{array}$ & Ceftriaxona & (III) \\
\hline $\begin{array}{l}\text { Grupo } 3 a \text {, pacientes con NAC grave que requieren internación en } \\
\text { UCl, sin riesgo de NAC causada por } P \text {. aeruginosa }\end{array}$ & $\begin{array}{l}\text { Combinaciones de aminopenicilina/ inhibidor } \\
\text { de } \beta \text {-lactamasas + un macrólido o una } \\
\text { "fluoroquinolona respiratoria" (levofloxacina o } \\
\text { moxifloxacina iv). Con positividad para antígeno de } \\
\text { Legionella, se prefiere levofloxacina o moxifloxacina } \\
\text { sobre los macrólidos y se recomienda tratamiento } \\
\text { combinado con macrólidos en pacientes en shock }\end{array}$ & $(\mathrm{I}, \mathrm{II}, \mathrm{III})$ \\
\hline $\begin{array}{l}\text { Grupo } 3 b \text {, pacientes con NAC grave que requieren internación en } \\
\mathrm{UCl} \text {, con riesgo de NAC causada por } P \text {. aeruginosa }\end{array}$ & $\begin{array}{l}\text { Cefepime o piperacilina / tazobactam + amikacina } \\
\text { y un macrólido o más levofloxacina (si no está } \\
\text { disponible, se podría utilizar ciprofloxacina en su } \\
\text { lugar) como opción principal }\end{array}$ & (II, III) \\
\hline Neumonía por aspiración & $\begin{array}{l}\text { Combinaciones de aminopenicilina / inhibidor de } \\
\beta \text {-lactamasas (iv) }\end{array}$ & (II, III) \\
\hline
\end{tabular}




\section{Característica}

Ninguna

Confusión

Frecuencia respiratoria $\geq 30$ respiraciones $/ \mathrm{min}$

Presión arterial sistólica $<90 \mathrm{~mm}^{3}$

Edad $>65$ años de edad
Puntaje

0

1

1

1

1
Puntos acumulados (Puntaje CRB-65)

0

1

2

3

4
Probabilidad de muerte (\%)

0,9

5,2

12,0

31,2

31,2

Adaptado de Bauer TT, et al. J Intern Med. 2006; 260: 93-101.

SMART-COP

Herramienta para la predicción de la posibilidad de los pacientes con neumonía adquirida en la comunidad (NAC) para requerir apoyo intensivo respiratorio o vasopresor (intensive respiratory or vasopressor support - IRVS)

\section{NAC confirmada con radiografía de tórax}

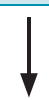

$\begin{array}{lll}\text { S } & \text { PA sistólica }<90 \mathrm{mmHg} & \square \text { (2 puntos) } \\ \text { M } & \text { Compromiso multilobar en Rx de tórax } & \square \text { (1 punto) } \\ \text { A } & \text { Albúmina }<3,5 \mathrm{~g} / \mathrm{dl}^{*} & \square(1 \text { punto) } \\ \mathbf{R} & \text { Frecuencia respiratoria }- \text { Corte ajustado por edad } & \square \text { (1 punto) }\end{array}$

\begin{tabular}{c|c|c} 
Edad & $\leq 50$ años & $>50$ años \\
\hline FR & $\geq 25 \mathrm{resp} / \mathrm{min}$ & $\geq 30 \mathrm{resp} / \mathrm{min}$
\end{tabular}

$\begin{array}{lll}\text { T } & \text { Taquicardia } \geq 125 \mathrm{lpm} & \square \text { (1 punto) } \\ \text { C } & \text { Confusión (reciente) } & \square \text { (1 punto) } \\ \text { - } & \text { Oxígeno bajo - Corte ajustado por edad } & \square \text { (2 puntos) }\end{array}$

\begin{tabular}{l|l|l} 
Edad & $\leq 50$ años & $>50$ años \\
\hline $\mathrm{PaO}_{2}{ }^{*}$ & $<70 \mathrm{mmHg}$ & $<60 \mathrm{mmHg}$ \\
\hline${\mathrm{O} \text { Saturación de } \mathrm{O}_{2}}_{\mathrm{O}\left(\text { si está con } \mathrm{O}_{2}\right): \mathrm{PaO}_{2} / \mathrm{FiO}_{2}{ }^{*}}$ & $\leq 333 \%$ & $\leq 90 \%$ \\
\hline
\end{tabular}

P $\quad \mathrm{pH}$ Arterial $<7,35^{*} \mathrm{mmHg}$

$\square$ (2 puntos)

$0-2$ puntos: Bajo riesgo de necesidad de IRVS

3 - 4 puntos: Riesgo moderado (1 en 8) de necesidad de IRVS

$5-6$ puntos: Riesgo alto ( 1 en 3 ) de necesidad de IRVS

$\geq 7$ puntos: Riesgo muy alto ( 2 en 3 ) de necesidad de IRVS

Adaptado de Charles P, et al. Clin Infect Dis 2008; 47: 375-84.

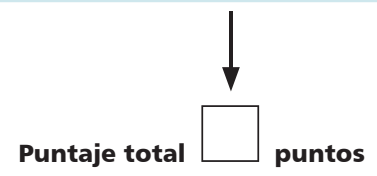

Interpretación:

* Para los médicos de asistencia primaria, los resultados de albúmina, pH arterial y $\mathrm{PaO}_{2}$ pueden obviarse y utilizarse la siguiente interpretación: 0 puntos: Muy bajo riesgo de necesidad de IRVS

1 punto : Bajo riesgo (1 en 20) de necesidad de IRVS

2 puntos: Riesgo moderado ( 1 en 10) de necesidad de IRVS

3 puntos: Riesgo alto (1 en 6) de necesidad de IRVS

$\geq 4$ puntos: Riesgo alto ( 1 en 3 ) de necesidad de IRVS 
Criterios modificados de la Sociedad Americana del Tórax (American Thoracic Society) para definir neumonía grave adquirida por adultos en la comunidad

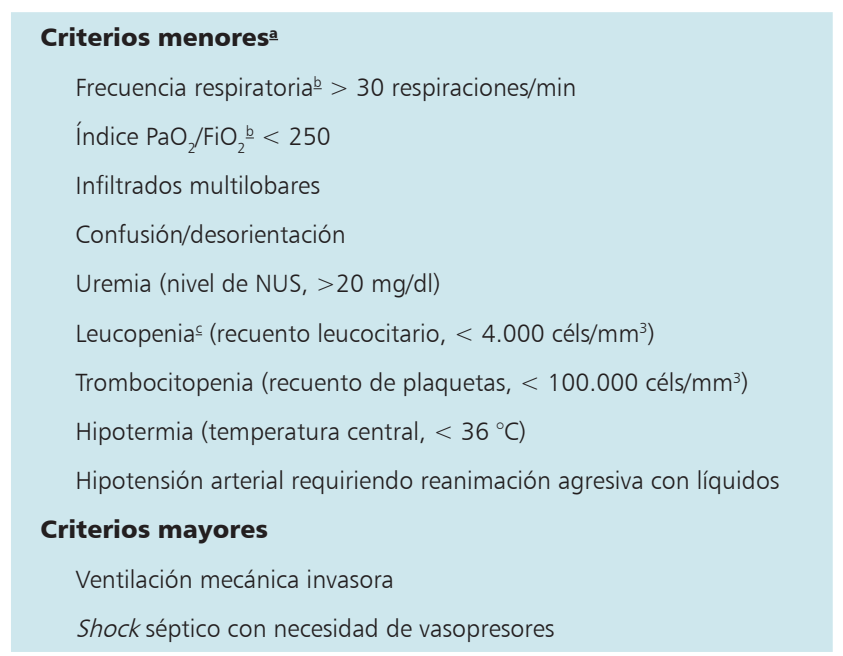

Adaptado de Mandell L, et al. Clin Infect Dis 2007;44: S27-S72.

NOTA. NUS, nitrógeno ureico en sangre; $\mathrm{PaO}_{2} / \mathrm{FiO}_{2}$, presión arterial de oxígeno/fracción de oxígeno inspirado.

atros criterios a considerar incluyen hipoglicemia ( en pacientes sin diabetes mellitus), alcoholismo agudo/deprivación aguda de alcohol, hiponatremia, acidosis metabólica inexplicada o aumento del nivel de lactato, cirrosis y asplenia.

bLa necesidad de ventilación no invasora puede sustituir la frecuencia respiratorio $>30$ respiraciones/min o un índice $\mathrm{PaO}_{2} / \mathrm{FiO}_{2}<250$.

‘Como resultado de infección solamente. 